\title{
Using Participatory Design Methodologies to Co-Design and Culturally Adapt the Spanish Version of the Mental Health eClinic: Qualitative Study
}

Laura Ospina-Pinillos ${ }^{1,2}$, MD; Tracey Davenport ${ }^{1}$, BA (Hons), EMBA; Antonio Mendoza Diaz ${ }^{3}$, BPsych, PhD; Alvaro Navarro-Mancilla ${ }^{4}$, MIPH, MD; Elizabeth M Scott ${ }^{5}$, MBBS, FRANZCP; Ian B Hickie ${ }^{1}$, MD, FRANZCP

\footnotetext{
${ }^{1}$ Brain and Mind Centre, The University of Sydney, Sydney, NSW, Australia

${ }^{2}$ Department of Psychiatry and Mental Health, Pontifical Javeriana University, Bogota, Colombia

${ }^{3}$ School of Psychiatry, Department of Medicine, University of New South Wales, Sydney, NSW, Australia

${ }^{4}$ Neuropsychiatry Research Group, Autonomous University of Bucaramanga, Bucaramanga, Colombia

${ }^{5}$ School of Medicine, University of Notre Dame Australia, Sydney, NSW, Australia
}

\section{Corresponding Author:}

Laura Ospina-Pinillos, MD

Brain and Mind Centre

The University of Sydney

Shops 1-3, 66-70 Parramatta Road

Sydney, NSW, 2051

Australia

Phone: 610286276946

Email: laura.ospinapinillos@sydney.edu.au

\section{Related Article:}

This is a corrected version. See correction statement in: http://mhealth.jmir.org/2022/3/e37679/

\begin{abstract}
Background: The Mental Health eClinic $(\mathrm{MHeC})$ aims to deliver best-practice clinical services to young people experiencing mental health problems by making clinical care accessible, affordable, and available to young people whenever and wherever they need it most. The original $\mathrm{MHeC}$ consists of home page with a visible triage system for those requiring urgent help; a online physical and mental health self-report assessment; a results dashboard; a booking and videoconferencing system; and the generation of a personalized well-being plan. Populations who do not speak English and reside in English-speaking countries are less likely to receive mental health care. In Australia, international students have been identified as disadvantaged compared with their peers; have weaker social support networks; and have higher rates of psychological distress. This scenario is acquiring significant relevance as Spanish-speaking migration is rapidly growing in Australia, and the mental health services for culturally and linguistically diverse populations are limited. Having a Spanish version (MHeC-S) of the Mental Health eClinic would greatly benefit these students.
\end{abstract}

Objective: We used participatory design methodologies with users (young people aged 16-30 years, supportive others, and health professionals) to (1) conduct workshops with users to co-design and culturally adapt the $\mathrm{MHeC}$; (2) inform the development of the MHeC-S alpha prototype; (3) test the usability of the MHeC-S alpha prototype; (4) translate, culturally adapt, and face-validate the MHeC-S self-report assessment; and (5) collect information to inform its beta prototype.

Methods: A research and development cycle included several participatory design phases: co-design workshops; knowledge translation; language translation and cultural adaptation; and rapid prototyping and user testing of the $\mathrm{MHeC}-\mathrm{S}$ alpha prototype.

Results: We held 2 co-design workshops with 17 users (10 young people, 7 health professionals). A total of 15 participated in the one-on-one user testing sessions ( 7 young people, 5 health professionals, 3 supportive others). We collected 225 source documents, and thematic analysis resulted in 5 main themes (help-seeking barriers, technology platform, functionality, content, and user interface). A random sample of 106 source documents analyzed by 2 independent raters revealed almost perfect agreement for functionality (kappa=.86; $\mathrm{P}<.001)$ and content (kappa=.92; $\mathrm{P}<.001)$ and substantial agreement for the user interface (kappa=.785; $\mathrm{P}<.001)$. In this random sample, no annotations were coded for help-seeking barriers or the technology platform. Language was identified as the main barrier to getting medical or psychological services, and smartphones were the most-used device to access 
the internet. Acceptability was adequate for the prototype's 5 main elements: home page and triage system, self-report assessment, dashboard of results, booking and video visit system, and personalized well-being plan. The data also revealed gaps in the alpha prototype, such as the need for tailored assessment tools and a greater integration with Spanish-speaking services and communities. Spanish-language apps and e-tools, as well as online mental health information, were lacking.

Conclusions: Through a research and development process, we co-designed and culturally adapted, developed and user tested, and evaluated the MHeC-S. By translating and culturally adapting the $\mathrm{MHeC}$ to Spanish, we aimed to increase accessibility and availability of e-mental health care in the developing world, and assist vulnerable populations that have migrated to English-speaking countries.

(J Med Internet Res 2019;21(8):e14127) doi: $\underline{10.2196 / 14127}$

\section{KEYWORDS}

telemedicine; medical informatics; eHealth; mental health; cultural characteristics; cultural competency; ethnic groups; transients and migrants; quality of health care; international students; Hispanics; Latinos; community-based participatory research; primary health care; patient participation; patient preference; patient satisfaction; consumer health information

\section{Introduction}

\section{Background}

The need for mental health services far outweighs the capacity of service providers all over the world [1]. Access to adequate-quality mental health care is also limited for many populations but is particularly limited for vulnerable groups such as the elderly and youth populations, racial and ethnic minorities, the socioeconomically disadvantaged, and rural populations [2]. Limited access to services is of particular concern for young people, as it is well established that $75 \%$ of the serious mental diseases and substance use problems emerge before 25 years of age [3]. When young people do seek and receive help, timely and evidence-based treatments are encountered by only a small proportion; in some low- and middle-income countries, the treatment gap can be as high as $90 \%$ [4].

Populations who do not speak English in English-speaking countries are less likely to receive mental health care [5]. In Latino populations with mental health problems, the lack of English proficiency is one of the biggest barriers when accessing services [6]. In Australia, non-English-speaking migrant populations struggle to access and understand the local health care system [7]. Language proficiency has been identified as a true barrier for migrant men when using services [8].

\section{International Students}

Australia is a popular study destination for students around the world. Most of Australia's international students are enrolled in the higher education sector $(44 \%)$, followed by the vocational education and training sector (27\%), and English-language intensive courses for overseas students (19\%) [9]. Studying abroad can be one of the most remarkable and rewarding experiences, but it can also be a source of great distress. The way migration is experienced by each individual highly depends on the push and pull factors that precipitated the migration [10]. In the case of international students, a high motivation to study in a different country can act as a protective factor, but the cultural distance of the host country, the lack of social support, and academic pressure can be powerful stressors. Consequently, several studies have shown increased rates of mental health problems in this population [10-12].
In Australia, international students have been identified to be disadvantaged compared with their peers; have weaker social support networks; have higher rates of psychological distress [13]; and are at higher risk of experiencing an adjustment disorder or other mental health problems [14]. The "International Student Welfare in Australia" report suggested that Australia does not adequately protect international students' human rights and highlights mental health as a key area of concern [15]. Recently, awareness of these issues has been covered by Australian mass media due to 27 suicides in the international student population between 2009 and 2015; sadly, all were reportedly associated with low help-seeking behaviors (22\%) [16]. As international students are less likely to receive mental health care, the previously mentioned report encourages institutions to provide information, including available services and increased research in this area. However, most of the research has been focused on tertiary education students and none or very little has been dedicated to language students.

This scenario is acquiring a significant relevance in Australia, where the Spanish-speaking (including Latino) international student migration is rapidly growing. In 2016-2017, language student visa grants (subclass 570) increased by $16.8 \%$, where 3 Spanish-speaking countries (Colombia, Spain, and Chile) were situated in the top 10 countries of applications logged outside Australia [17].

\section{Health Information Technologies}

The internet and new and emerging technologies hold enormous promise for significantly expanding the reach of adequate-quality mental health care by addressing several barriers [18]. Interventions delivered through these technologies have the potential to reach a wide geographic area via remote delivery of care [19]; decrease costs in delivering self-help and social networking interventions; and allow for relatively rapid, centralized scaling up of interventions to a public health dissemination level [20]. English-language, Web-based mental health interventions have proven to be effective for self-screening and referral [6], reducing symptoms and delivering effective treatment for major mental health disorders [21]. A large number of studies, including randomized controlled trials, have also demonstrated the effectiveness of various internet-delivered interventions, such as psychotherapy and psychoeducation [22], treating problematic health behaviors 
[23], and delivering prevention and treatment programs [24]. Other population-based studies have reported that Web-based tools can enhance the delivery of mental health care in primary care settings [25] and support training and supervision for providers [26]. The number of programs available is growing rapidly [27]. Although positive results are seen from the use of self-directed electronic health interventions, increased effectiveness has been reported if they are used as part of a stepped-care model [28], with the support of a trained health professional [29] or as an adjunct to face-to-face treatment [30].

Despite the growth of such technologies in high-income countries, these technologies are still lacking in low- and middle-income countries and, more specifically, in the Spanish language [31]. Traditional telemedicine has supported the cooperation between developed and developing countries to deliver care across borders by linking professionals rather than providing direct connection between professionals and patients [32]. Telepsychiatry has been used to deliver mental health care to individuals requiring attention, not only locally [33-35], but also internationally, as a means to deliver care to Spanish-speaking individuals residing in a different country $[32,36,37]$. This type of care is a more efficient alternative, as it doesn't require the use of interpreters and is culturally sensitive [38]. Successful Spanish-language health information technology (HIT) interventions have been applied in several fields, such as cancer; diabetes; and child, infant, or maternal health [39]. Despite this, the HITs available for mental health are scarce. Initial reports have demonstrated their potential utility in the screening of mental health problems [40], as well as in the treatment of depression [31,41,42], anxiety [43], and substance use disorders [44].

Although the development of HITs in Spanish is recent, their usability and retainability among users is of concern [31]. Experience in other languages (mostly English) has demonstrated that participatory design research methodologies that involve stakeholders and end users in the design and development of these systems at all stages could finally increase user engagement and system usability [45-48]. A close collaboration with end users ensures the appropriateness of these systems for culturally and linguistically diverse populations [49]. Therefore, incorporating participatory design research methodologies that puts end users at the center of the design and development process is greatly needed for Spanish-language-based HITs.

\section{Objectives}

The University of Sydney's Brain and Mind Centre (Sydney, Australia) is a leader in the development of youth-specific mental health services [50,51] and evidence-based electronic health technologies to engage young people in their own care [52]. The Mental Health eClinic (MHeC) [48,53] was a prototypic Web-based tool designed and developed through a partnership between the Young and Well Cooperative Research Centre and the Brain and Mind Centre. The $\mathrm{MHeC}$ aimed to deliver best-practice clinical services to young people experiencing mental health problems by making clinical care accessible, affordable, and available to young people whenever and wherever they need it most. The original $\mathrm{MHeC}$ had 5 main elements: a home page with a visible triage system for those requiring urgent help; a comprehensive online physical and mental health self-report assessment; a detailed dashboard of results; a booking and videoconferencing system to enable video visits; and the generation of a personalized well-being plan that included links to evidence-based, young person-suggested, health professional-recommended apps and e-tools [53]. We hypothesized that having a Spanish version of the $\mathrm{MHeC}$ (MHeC-S) could greatly benefit young people who are native Spanish speakers living in Australia and who are actively seeking help.

Using a research and development cycle (including several participatory design phases) with end users (young people aged 16 to 30 years, supportive others [such as family, friends, caregivers, coaches, teachers, or community members], and health professionals) as a framework, in this study we aimed to (1) conduct co-design workshops with end users to co-design and culturally adapt the $\mathrm{MHeC}$ for Spanish-speaking young people based in Australia; (2) inform the development of the alpha prototype of the MHeC-S; (3) test the usability of the alpha prototype of the $\mathrm{MHeC}-\mathrm{S}$; (4) translate, culturally adapt, and face-validate the self-report assessment to a Spanish-speaking population based in Australia; and (5) collect information to inform the beta prototype of the MHeC-S.

\section{Methods}

\section{Participants}

Participants included community-based young people aged 16 to 30 years; native Spanish speakers living in Australia; and native Spanish-speaking young people attending headspace Camperdown and headspace Campbelltown (headspace Australia's National Youth Mental Health Foundation provides early intervention mental health services and assistance in enhancing young peoples' [aged 12-25 years] well-being; Camperdown and Campbelltown are 2 sociodemographic areas of Sydney, Australia). Additionally, native Spanish-speaking health professionals and supportive others participated. Participants were required to have regular access to a smartphone (with the iOS or Android operating system) and the internet.

The University of Sydney's Human Research Ethics Committee approved the study (Protocol No. 2014/689 for the co-design workshops and Protocol No. 2016/487 for the user testing sessions). Participants were provided with the relevant information about the study (participant information statement) before providing their consent and participating in the study. We also obtained parental consent for participants under 18 years of age. Young people received gift vouchers to thank them for their time and expertise when they attended the co-design workshops and the user testing sessions.

The recruitment strategy included the identification of potential participants through headspace Camperdown and headspace Campbelltown; poster and postcard advertisements displayed in community organizations; Facebook advertisements and a study-specific Facebook page; use of organizational social media channels; universities, institutes of technical and further 
education, language schools, and vocational and training institutes; and cooperation with Spanish-speaking consulates in Australia.

\section{Procedure}

We based the participatory design research methodology on the Young and Well Cooperative Research Centre's guide Participatory Design of Evidence-Based Online Youth Mental Health Promotion, Intervention and Treatment [54]. The research and development cycle used our previously established phases for co-design and build of the original version of the prototypic $\mathrm{MHeC}$ [53]. The process encompasses several participatory design phases: co-design workshops (phase 1); knowledge translation (phase 2); language translation and cultural adaptation (phase 3); rapid prototyping of the alpha prototype and user testing (phase 4); rapid prototyping and user (acceptance) testing of the beta prototype (phase 5); and real-world trialing of the final prototype (phase 6). This paper reports the initial 4 phases; we will report phase 5 and phase 6 separately (Figure 1).

Figure 1. Research and development cycle of the Spanish version of the Mental Health eClinic.

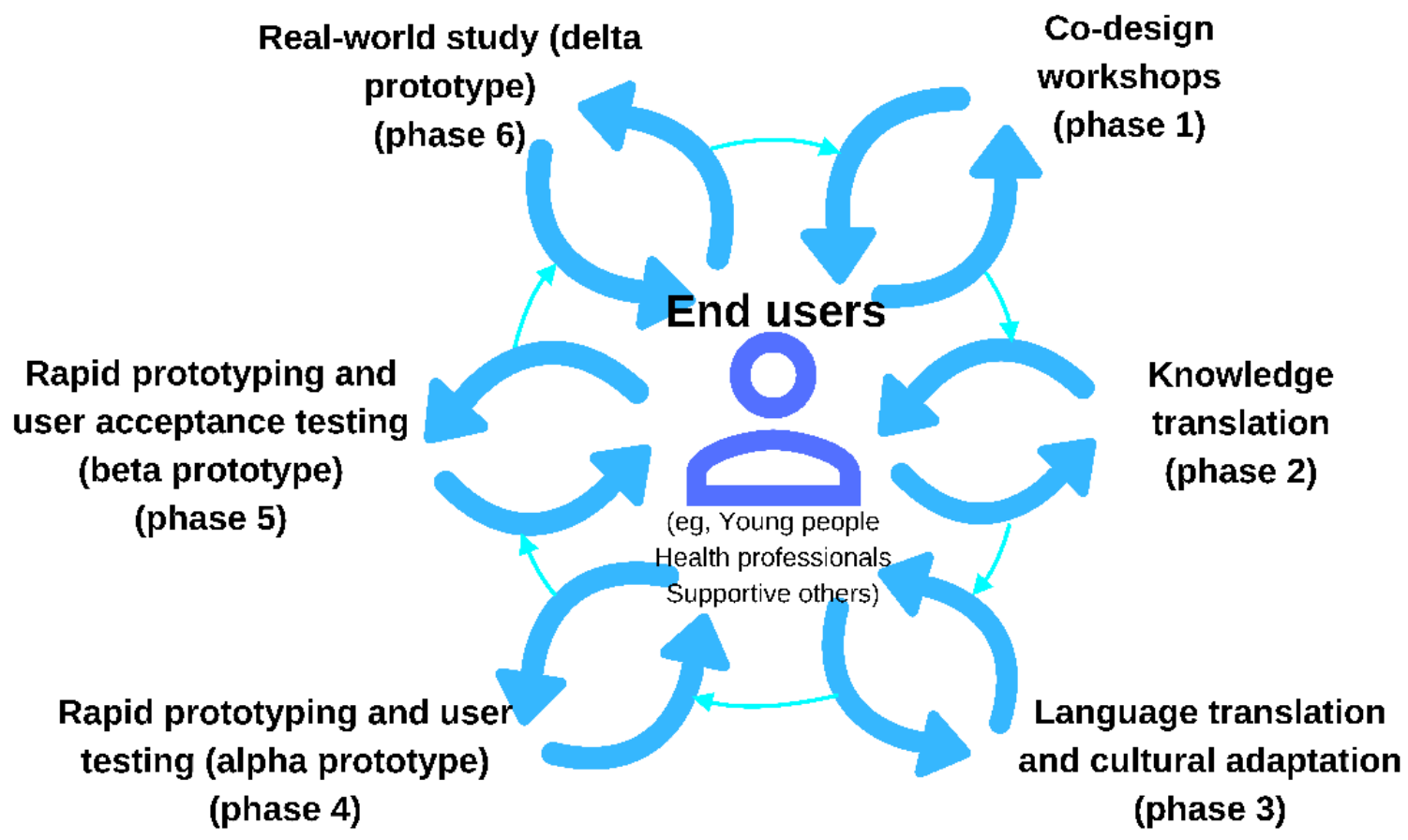

\section{Phase 1: Co-Design Workshops}

We held co-design workshops in 2 stages with a maximum of 10 participants per workshop; we ran these with young people and health professionals separately. We did not use technology in the workshops; instead, we conducted the following design activities to facilitate the process: we used design testing using mockups and end user sketching (Figure 2) to obtain information for the content, functionality, and the look and feel of the prototype.

The topics covered in each workshop included defining the advantages and disadvantages of having a Spanish version of the $\mathrm{MHeC}$; defining the barriers of having an $\mathrm{MHeC}-\mathrm{S}$; assessing the 5 main elements of the $\mathrm{MHeC}$; and defining the functionality and the user interface. At the end of each workshop, the knowledge translation team analyzed and synthetized the information. 
Figure 2. Samples of end user sketches made during a co-design workshop. (A) Hand-drawn sketch by a young person. (B) Hand-drawn sketch by a health professional.

A

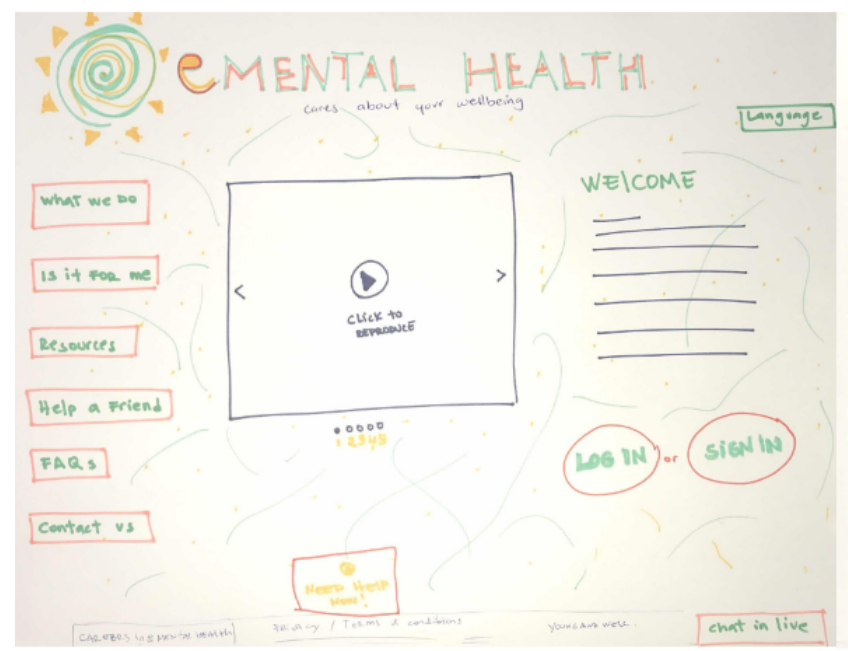

B
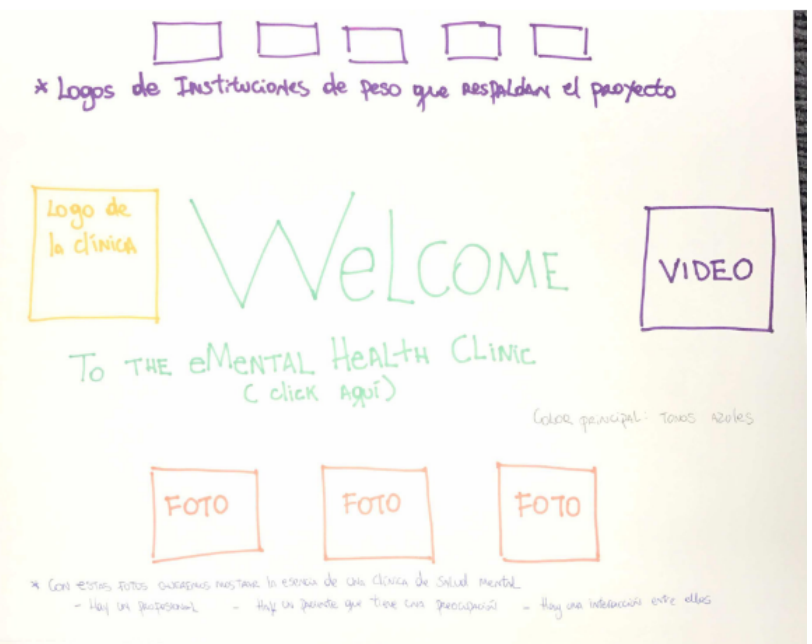

\section{Phase 2: Knowledge Translation}

The knowledge translation team independently analyzed the diagrams and notes taken from the previous phase (or workshop), then compared and discussed observations until they reached an agreement. They then synthesized the information by creating wireframes that would be used in the subsequent phase.

\section{Phase 3: Language Translation and Cultural Adaptation}

\section{Language of the Prototype}

For all of the prototype's language, a native Spanish-born psychiatrist (LOP) performed a simple translation. Then, for general-content items, 2 Spanish-born psychologists (not involved in the publication of this paper) reviewed the translations. A second Spanish-born psychiatrist (ANM) also reviewed specific mental health content or sensitive content such as the dashboard of results and psychoeducational factsheets. Discrepancies between the translations were resolved by consensus in the group.

\section{Translation and Cultural Adaptation of the Self-Report Assessment}

Understanding the great need for health professionals and researchers to have available, reliable, and valid measures across different languages and populations, we aimed to translate, back-translate, culturally adapt, and face-validate the Australian self-report assessment using a modified version of the "user-friendly guideline for the translation, adaptation and validation of instruments or scales for cross-cultural health care research" developed by Sousa and Rojjanasrirat [55].

Two Spanish bilingual health professionals (LOP and ANM) independently translated all (health-related) items from English to colloquial Spanish, with the exception of standardized surveys already available in Spanish. A third native Spanish-born psychologist (AMD) reviewed the translated versions and the original English versions. Then, in group discussions, we ensured that all items were linguistically and culturally appropriate by assessing the face-validity of each item in the self-report assessment, as well as assessing the readability and grammatical consistency of the entire assessment. All items were then back-translated to English by one Australian adult (not involved in the publication of this paper) who is fluent in colloquial Spanish and is based in Colombia, has extensive research experience and tertiary qualifications in health, and is accredited to teach English to adults. Discrepancies between the original and back-translated versions were resolved in group sessions between the translators and back-translator.

A literature review was undertaken (by LOP) to identify relevant measures for this population, as well as those instruments already translated and validated into Spanish. The review included both published (identified via PubMed, Google Scholar, SciELO, and LILACS) and gray literature (identified via Google Advanced search) in both English and Spanish. Understanding that some questionnaires might have several translations or versions, we established the following process to select the instruments: first, we selected official translations; if these were unavailable, we selected versions of the published translation and psychometric processes. When more than 1 version or source was available, the 2 previously mentioned health professionals (LOP and ANM) by consensus selected the most appropriate to be included.

\section{Phase 4: Rapid Prototyping and Usability Testing of the Alpha Prototype}

Phase 4 involved user testing with end users: young people, health professionals, and supportive others. Sessions used laptops, tablets, and smartphones (with the iOS or Android operating system), where participants had access to the alpha prototype of the MHeC-S. In each 90-minute one-on-one user testing session, a researcher was paired with an end user. Using a think-aloud protocol [56], participants were observed as they navigated the prototype and responses were recorded to questions posed by the researcher about the main elements of the $\mathrm{MHeC}-\mathrm{S}$. A total of 4 usability tasks were completed in the session: (1) create an account and log in, (2) find the Need Help Now button, (3) explore the dashboard of results, and (4) book 
an appointment. Task completion (yes/no) and task difficulty were measured using the Single Ease Question (SEQ; responses ranged from "very difficult" to "very easy," rated from 1 to 7) [57]. User testing also explored the prototype's utility and the users' inclination to use the $\mathrm{MHeC}-\mathrm{S}$, overall comments, and naming of the prototype. Interviews and observations were transcribed. No instructions or clues were provided, and all responses and observations (eg, nonverbal cues) were transcribed.

\section{Data Analysis}

We simultaneously collected and analyzed data at the end of each phase in order to facilitate the process. Hence, we explored preliminary findings in the following phase. We determined interrater reliability and analyzed task difficulty using IBM SPSS Statistics for Mac 22.0 (IBM Corporation). We uploaded and analyzed source documents (workshop discussion notes, artifacts [mockups and end user sketches] and user testing notes) using thematic analysis techniques [58] in NVivo 11 for Mac (QSR International) [59]. The thematic analysis framework involved both inductive and deductive coding. Acknowledging that one of the biggest challenges in this project was the translation and cultural adaptation of the MHeC-S, in the deductive code framework we considered the adaptation of the prototype in 4 dimensions: technology platform, functionality, content, and user interface. As defined by Valdez et al in their culturally informed design framework [60], "technology platform" refers to the different types of hardware, "functionality" indicates the actions that can be performed, "content" refers to the message that is transmitted, and "user interface (design)" refers to the visual presentation of the content and functionality. We also enriched this type of coding with our previously established [53] codes (general elements of the $\mathrm{MHeC}$; general look and feel; privacy and data sharing; and interaction of the $\mathrm{MHeC}$ with social networks).

Data collection and qualitative analysis were done in Spanish. To facilitate reporting, we provide quotes translated from the original data. Multimedia Appendix 1 shows the original quotes in Spanish.

One researcher coded all the material (coder A: LOP) and a second coder (coder B: not involved in the publication of this paper) reviewed half of the collected documents in order to assess the reliability, assess consistency, and reduce potential bias [61]. We calculated interrater agreement for each theme using the Cohen kappa statistic on a binomial distribution (category present vs category not present) for each of the themes [62] and interpreted the obtained values using Viera and Garrett's criteria: kappa range .01 to .20 indicates slight agreement, kappa range .21 to .40 indicates fair agreement, kappa range .41 to .60 indicates moderate agreement, kappa range .61 to .80 indicates substantial agreement, and kappa range .81 to .99 indicates almost perfect agreement [63].

\section{Results}

\section{Workshops and Sessions}

In May 2015, we conducted 1 full-day co-design workshop with Spanish-speaking young people based in Australia and 1 full-day co-design workshop with Spanish-speaking health professionals based in Australia. In total, we conducted 3 knowledge translation sessions immediately after each workshop and at the end of the usability testing. The general-content translation process started in June 2015, and the self-report assessment literature review and translation process started in January 2016 and lasted until the end of the same year. We conducted 15 one-on-one user testing sessions between March and November 2017.

\section{Participant Characteristics}

A total of 10 young people participated in the co-design workshops; 8 were female and their ages ranged from 17 to 29 years (median age 24 years). Of the young participants, 8 were Colombian and 2 were Chilean. A total of 7 health professionals participated in the workshops; 6 were female and their ages ranged from 22 to 34 years (median age 28 years). Of the health professionals, 3 were from Colombia, 2 were from Chile, and 2 were from Spain.

A total of 15 participants participated in the one-on-one user testing sessions: 7 young people with ages ranging from 19 to 30 years (median age 26 years); 5 health professionals with ages ranging from 27 to 74 years (median age 35 years); and 3 supportive others with ages ranging from 30 to 57 years (median age 30 years). Of these participants, 10 were female and 12 were Colombian, while the rest were from Argentina, Spain, and Venezuela.

\section{Thematic Analysis}

We collected and analyzed a total of 225 source documents (2 workshop discussion notes and 208 artifacts produced by participants were collected in the co-design workshops plus 15 user testing notes) during the entire process.

\section{Coding Interrater Reliability}

Using inductive coding, 1 new main theme emerged (help-seeking barriers) and, from the deductive coding framework, 4 main themes were reiterated (technology platform, functionality, content, and user interface). Of the 225 source documents, $106(47.1 \%)$ were analyzed by both raters. A total of 378 annotations were recoded from both coders (coder A and coder B). Interrater agreement of functionality theme between coder A and coder B was "almost perfect" (kappa $=.86 ; P<.001)$, with concordance in a total of $93.7 \%$ (354/378) of the annotations. Similarly, we obtained an "almost perfect" agreement (kappa $=.92 ; P<.001)$ between raters in relation to the content theme, with $97.6 \%$ (369/378) of total concordance. In relation to interface, interrater agreement between coders was "substantial" (kappa $=.785 ; P<.001)$, with concordance in a total of $90.0 \%(340 / 378)$ of the annotations. In this random sample, no annotations were coded for help-seeking barriers or technology platform themes.

\section{Help-Seeking Barriers}

Within this domain, participant perceptions of the help-seeking barriers fell into 3 categories: the language barrier, problems recognizing symptoms or poor mental health literacy, and the availability and accessibility of sources of help. 


\section{Language Barrier}

All participants $(32 / 32,100 \%)$ highlighted language as the main barrier to getting medical or psychological services (Multimedia Appendix 1):

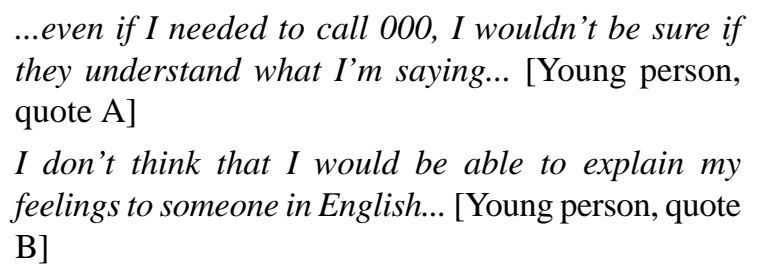

I don't think that I would be able to explain my feelings to someone in English... [Young person, quote B]

As the aim for most of these students was to learn English (or improve their English level), their communication skills were, in general, limited. This was a source of distress, as they felt limited in their day-to-day living:

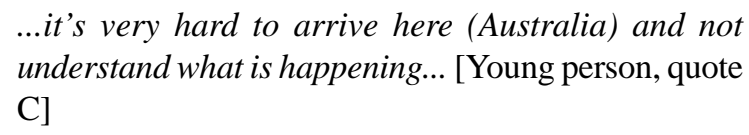

For some, the language barrier could have a very negative impact on their confidence:

\section{...it's like in English I'm a different person; sometimes I feel people think I'm dumb... [Young person, quote E]}

...the impact on their [international students] confidence is huge. Sometimes I have to remind him [international student] what he is capable of... [Health professional, quote $\mathrm{F}$ ]

\section{Problems Recognizing Symptoms or Poor Mental Health Literacy}

International students face different issues during migration that could have an impact on their well-being. Participants felt concerned for those who have recently arrived in Australia, as they are perceived as being more vulnerable. According to these participants, a great majority experienced some degree of cultural shock upon their arrival; getting used to regular things such as food, climate, and transport can be relevant stressors among students.

...it is hard to try to fit, and try to understand how

things work here... [Young person, quote G]

As Australia's cost of living is high, all participants reported economic concerns $(32 / 32,100 \%)$, whereas some $(17 / 32,53 \%)$ experienced difficulties with housing, getting a job (or a job with fair work conditions), or establishing relationships with peers. All these factors put the students at a higher risk of adaptational problems, which are often unnoticed.

Additionally, the conditions of migration greatly affect individuals' experience in a new country. Some common negative factors were visiting another country for the first time, travelling alone, and not having family members or friends already residing in that country. Most international students need to work to pay their expenses; however, the jobs they find to support their stay are often not related to their already acquired skills, as a young person explained:

...the majority [of] us have Bachelor degrees in our home countries...so when we arrive in Australia, the jobs we find are very different from what we have been trained in-most of us have to work cleaning, or as a waitress or in construction [Young person, quote $\mathrm{H}]$

For many young people, reconciling this discrepancy is challenging.

\section{Availability and Accessibility of Sources of Help}

All 12 health professionals and all 3 supportive others believed that international students have a great need for Spanish-language-based mental health services in Australia. They perceived that the cases of young people requiring help are increasing, as a supportive other explained:

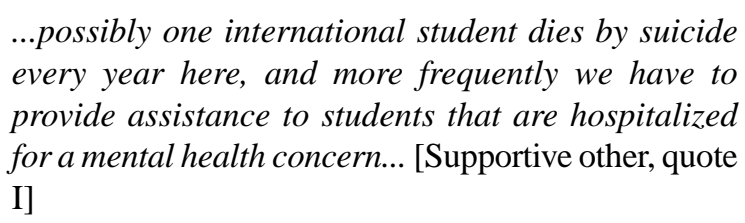

Young people believed that having an $\mathrm{MHeC}-\mathrm{S}$ would be of great utility, as they struggle to understand Australia's health system and are not aware of their Overseas Student Health Cover benefits. All young participants (17/17, 100\%) knew Australia's national emergency phone number (000). However, just a few $(7 / 17,41 \%)$ of them understood where to go if they needed nonurgent medical care, and all of them stated that they didn't know where to get psychological assistance.

All 17 young people said they would use a system like the $\mathrm{MHeC}-\mathrm{S}$, as they felt it would be a tool to increase mental health awareness and access to sources of help. Additionally, students believed they would be more inclined to use the MHeC-S if they knew about it beforehand, perhaps in the information they receive before arriving in Australia. All 12 health professionals imagined the prototype acting as a bridge between established services and centers in Australia such as the Transcultural Mental Health Centre; New South Wales (NSW) Service for the Treatment and Rehabilitation of Torture and Trauma Survivors; Translating and Interpreting Service; NSW Spanish and Latin American Association for Social Assistance; other relevant cultural associations; and diplomatic missions.

In relation to online sources of help, participants stated that Google was their main source for getting information about their health symptoms. However, they did not necessarily trust all the information they obtained. Participants agreed that there is a shortage of Spanish-language online information (from reputable sources such as universities and organizations) and, more specifically, trustworthy apps and e-tools.

\section{Technology Platform}

All participants $(32 / 32,100 \%)$ reported that they had constant access to the internet via mobile data plans or Wi-Fi networks. The most commonly used device to access the internet was a smartphone $(32 / 32,100 \%)$, followed by a laptop. All participants agreed that the $\mathrm{MHeC}-\mathrm{S}$ needs to be accessible via a mobile 
device in order to really respond to this population's needs, as some of the students did not have a desktop, laptop, or tablet. All 17 young people reported that mobile phones and the internet were necessary tools in this period of their life, as they used them to communicate with English-speaking people and keep in contact with family and friends overseas. Additionally, they used them in their daily activities (eg, a global positioning system feature), or as a way to find a job or accommodation. As a consequence, they highlighted the importance of the $\mathrm{MHeC}-\mathrm{S}$ having a responsive Web design, where the prototype needs to work on mobile devices; otherwise, access would be jeopardized.

\section{Functionality}

There was adequate acceptability of the 5 main elements of the MHeC-S: a home page with a visible triage system for those requiring urgent help; a comprehensive online physical and mental health self-report assessment; a detailed dashboard of results; a booking and videoconferencing system to enable video visits; and the generation of a personalized well-being plan that includes links to evidence-based, young person-suggested, health professional-recommended apps and e-tools.

\section{Element 1: Home Page and Triage System}

When shown the home page, participants (15/32, 47\%) suggested that the MHeC-S webpage's domain should be ".com" or ".org," as this would increase the website's credibility. At the same time, they wanted the home page to display all relevant $\operatorname{logos}$ of affiliated organizations such as the logo of the University of Sydney and relevant Latin American or Spanish universities associated with the $\mathrm{MHeC}-\mathrm{S}$. In this space, they wanted to find a simple description of "....what the MHeC-S has to offer..." (young person, quote $\mathrm{J}$ ) and perhaps a series of short videos that explain more about the $\mathrm{MHeC}-\mathrm{S}$ and also contained testimonials. As language might be a concern, participants suggested adding a settings cog on the home page so they could choose their language and, consequently, relevant content would also be prompted. The triage system was widely accepted, as all users understood the need for screening for urgent services and for rapid referral of users (Figure 3).

Figure 3. Home page and triage system.

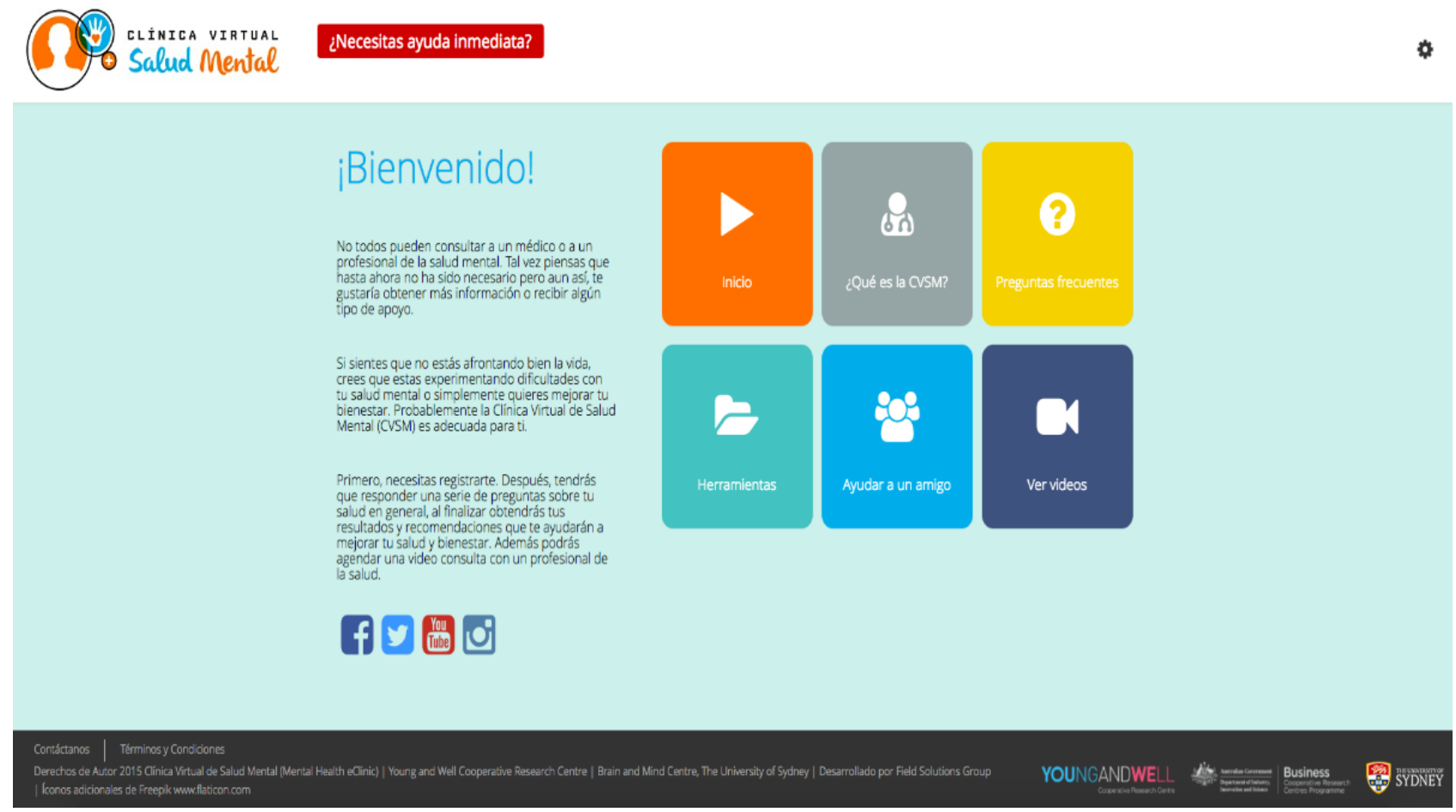

\section{Element 2: Online Physical and Mental Health Self-Report Assessment}

When shown the assessment (via questionnaire) (Figure 4), participants liked that the online physical and mental health assessment used rule-based decision algorithms that enable personalization of the assessment to the young person's needs (eg, sex-specific questions or in-depth assessments according to positive screening responses) and inform the dashboard of results. They also accepted the established features of pausing and resuming later, as they would give participants more flexibility to complete the assessment where and when they prefer. Additionally, participants approved the type of questions (eg, Likert-type scale questions and 2-way closed-ended questions) contained in this assessment. However, health professionals $(12 / 12,100 \%)$ suggested including 1 open-text question at the beginning of the assessment with the aim of assessing the reason for accessing the MHeC-S that day, as one clinician explained:

I would like to know the reason [why the young person was] visiting the $\mathrm{MHeC}$-S...as we do in practice assessing the presenting or chief complaint... [Clinician, quote $\mathrm{K}$ ] 
Figure 4. Online physical and mental health self-report assessment.

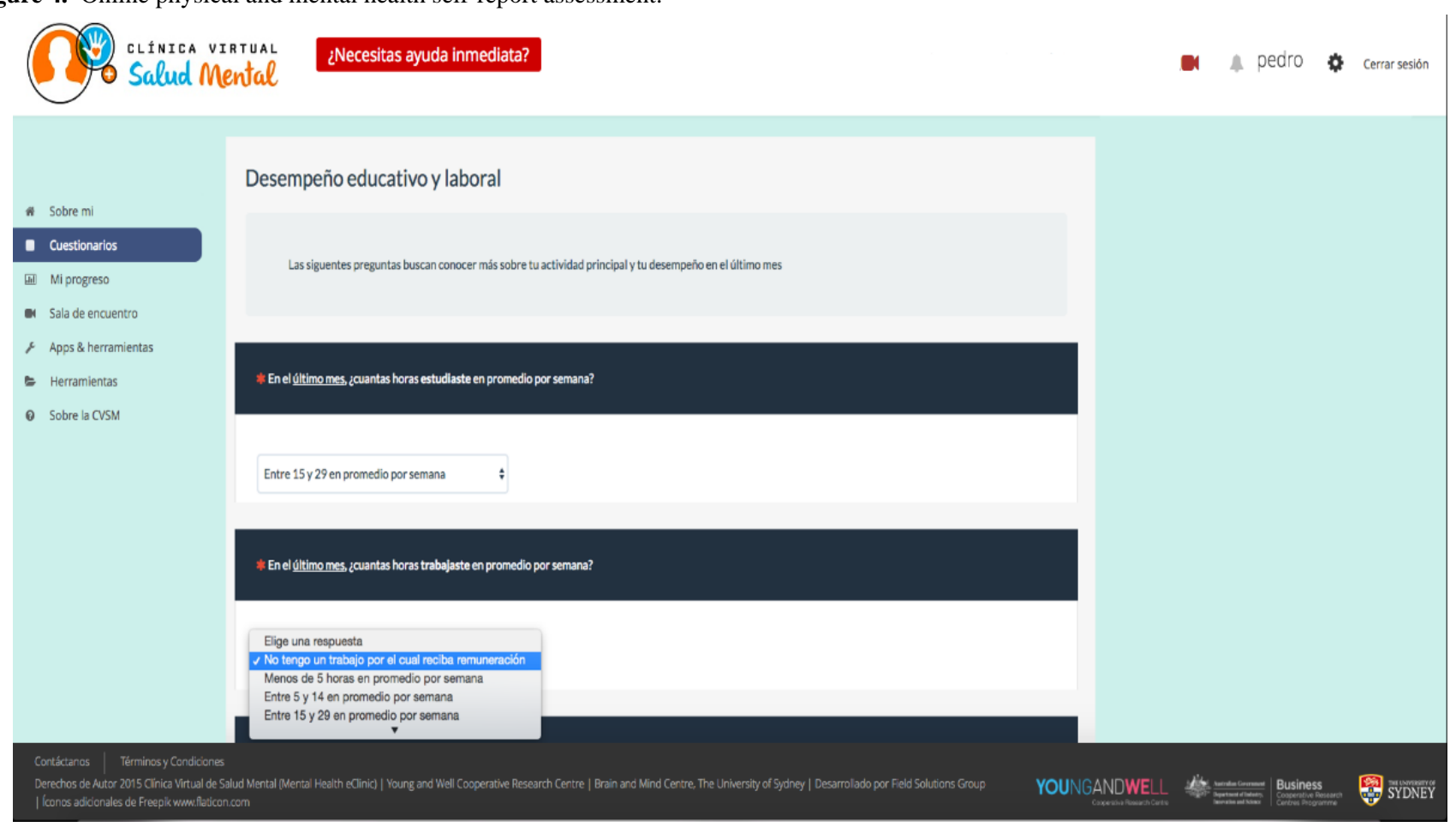

\section{Element 3: Dashboard of Results and Progress}

All 32 participants agreed that after completion of the online self-report assessment a dashboard of results should be displayed immediately (Figure 5). Participants accepted the simple bar and line graphs, colored icons, and traffic light representations, and reported that they were easy to understand. Health professionals $(12 / 12,100 \%)$ believed that the assessment and the dashboard of results were useful tools to inform their practice, not only in their first assessment but also as an ongoing form of care. In relation to the dashboard's language, participants preferred the use of lay terms instead of medical terminology. When medical jargon is needed (eg, psychosis or hypomania), participants proposed that the prototype should display a simple explanation of the term when they click on the word or hover over it.

Figure 5. Dashboard of results and progress.

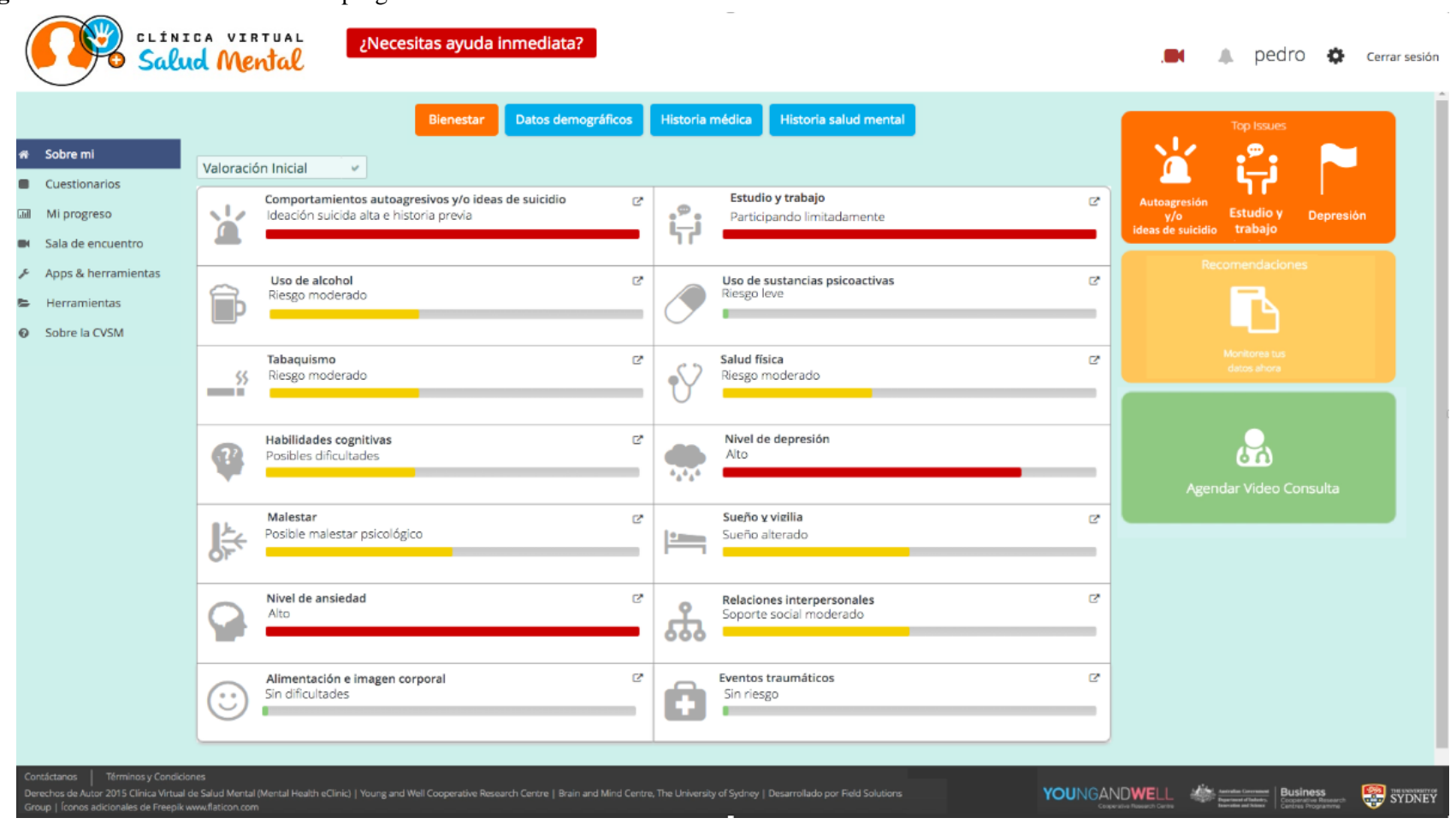




\section{Element 4: Booking System and Video Visit System}

All participants agreed that the booking and video visit system embedded in the $\mathrm{MHeC}-\mathrm{S}$ (Figure 6) was a secure way of protecting privacy. Due to the limited numbers of Spanish-speaking health professionals in Australia, participants believed that having a video visit with a Spanish-speaking health professional would be an effective way of screening and assessment, as well as providing (and receiving) advice, treatment, and therapy. Importantly, they acknowledged that video visits would be more efficient, as this would save them time and money, as a young person explained: ...we will know exactly where to go and not to waste time going from one place to another, searching for someone that understands me... [Young person, quote L]

Furthermore, the prototype provided them with security, as a health professional explained:

...they can always know where to go, like a secure base... [Health professional, quote $\mathrm{M}$ ]

Figure 6. Booking system and video visit system.

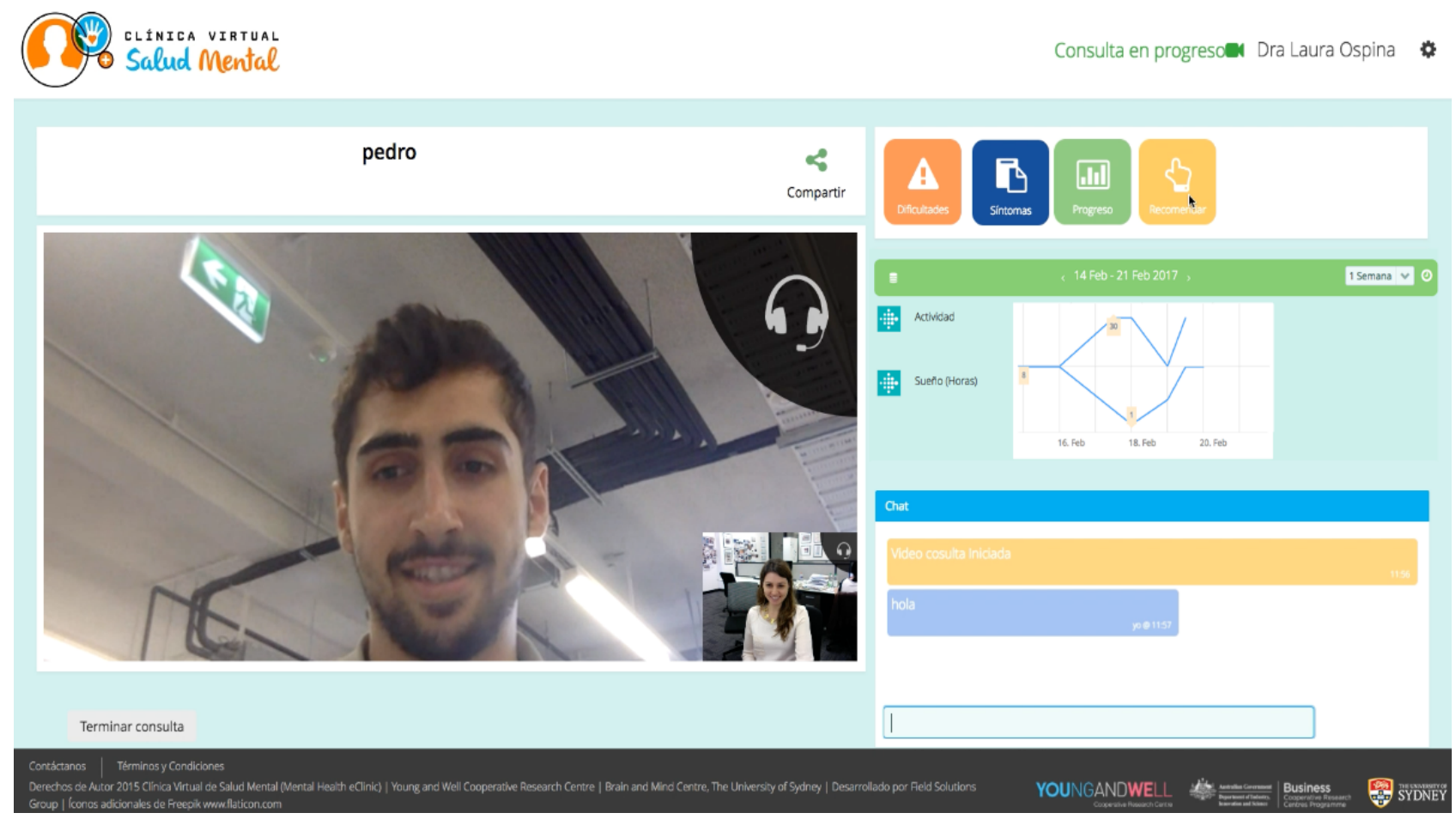

\section{Element 5: Personalized Well-Being Plan That Includes Links to Evidence-Based, Young Person-Suggested, Health Professional-Recommended Apps and E-Tools}

The idea of having a tailored plan and recommendations immediately after the completion of the self-report assessment was widely accepted by participants $(32 / 32,100 \%)$ (Figure 7$)$. Young people $(17 / 17,100 \%)$ said that they would be likely to download and use the recommended apps and e-tools if those matched with their needs. However, most of the participants $(29 / 32,91 \%)$ highlighted a lack of Spanish-language apps and e-tools . Young people $(17 / 17,100 \%)$ said that they would try to use an app in English, but they also recognized that their experience and the benefit would be limited, especially for those apps that have audio resources, as one young person explained:

I would try to use it as much as I can, but I think there are going to be many things I don't understand-for example, the mindfulness audios... [Young person, quote N.]

As potential solutions, participants proposed the creation of videos that contain general information, as well as relaxation and breathing exercises; a detailed directory that describes available English apps and e-tools; and, ideally, the development of several Spanish-language apps, e-tools, and Spanish adaptations of the best evidence-based resources. 
Figure 7. Personalized well-being plan that includes links to evidence-based, young person-suggested, health professional-recommended apps and e-tools.

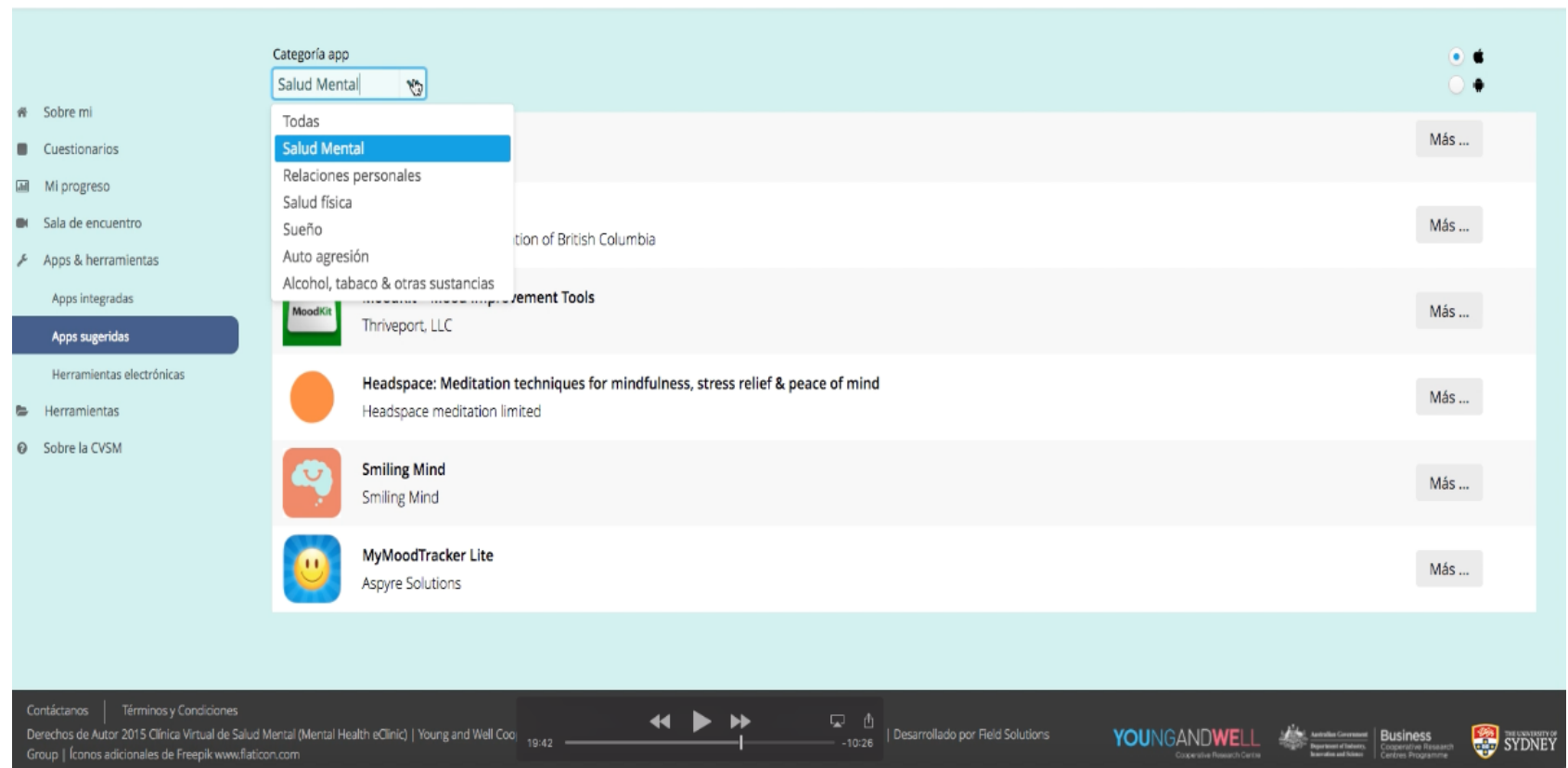

\section{Content: Translation and Cultural Adaptation of the Self-Report Assessment}

The self-report assessment included 16 modules (Table 1 [64-89]) with smart skips built in so that it was tailored to each individual and took a minimum amount of time to complete (approximately 45 minutes).

The self-report assessment translation process started in early 2016, with the literature review. We found 8 Spanish-translated versions of measures from the original source: the 2-step method to measure transgender identity [90], 10-item Kessler Psychological Distress Scale [91], Quick Inventory of Depressive Symptomatology [92,93], Community Assessment of Psychic Experiences [94,95], Alcohol Use Disorders Identification Test [96], Alcohol, Smoking and Substance Involvement Screening Test [97], International Physical Activity
Questionnaire [98,99], and the Spanish version of the World Mental Health Composite International Diagnostic Interview used in the National Comorbidity Survey Replication Adolescent Supplement [100,101]. We selected 5 because we found their translation and psychometric properties in the academic literature: the Primary Care Posttraumatic Stress Disorder (PTSD) Screen [102], PTSD Checklist-Civilian Version [103], Altman Self-Rating Mania Scale [104], the Cutting down, Annoyance by criticism, Guilty feeling, and Eye-openers questionnaire (which has been widely used in several Spanish-speaking studies and several versions are available online [105,106]; we used the Colombian version for its methods [107]), and the Fagerström Test for Nicotine Dependence [108]. Although we didn't find any versions of the empathy quotient scale in the academic literature, we found a Spanish version provided by the Autism Research Centre of the University of Cambridge [109]. 
Table 1. Self-report assessments in each of the 19 modules.

\begin{tabular}{|c|c|c|}
\hline \multicolumn{2}{|c|}{ Module } & \multirow{2}{*}{$\begin{array}{l}\text { Questionnaires } \\
\text { Short open-text question }\end{array}$} \\
\hline 1. & Main reason for visiting the $\mathrm{MHeC}-\mathrm{S}^{\mathrm{a}}$ & \\
\hline 2. & General demographics & $\begin{array}{l}\text { Items derived from the Second Australian Young and Well National Survey [64] and the 2-step } \\
\text { method to measure transgender identity [65] }\end{array}$ \\
\hline 3. & Social and occupational function & $\begin{array}{l}\text { Modified versions of the Brief Disability Questionnaire [66] and the self-report version of the } \\
\text { Social and Occupational Functioning Assessment Scale [67] }\end{array}$ \\
\hline 4. & Psychological distress & 10-item Kessler Psychological Distress Scale [68] \\
\hline 5. & Depressed mood & Quick Inventory of Depressive Symptomatology (QIDS-SR-16) [69] \\
\hline 6. & Anxiety & Overall Anxiety Severity and Impairment Scale [70] \\
\hline 7. & Mania-like experiences & Items derived from the Altman Self-Rating Mania Scale [71] \\
\hline 8. & Psychosis-like experiences & $\begin{array}{l}\text { Items derived from the Community Assessment of Psychic Experiences-Positive Symptoms } \\
\text { Scale [72] }\end{array}$ \\
\hline 9. & Traumatic experiences & Primary Care PTSD ${ }^{\mathrm{b}}$ Screen [73] and the PTSD Checklist-Civilian Version [74] \\
\hline 10. & Self-harm behaviors and suicidal ideation & Suicidal Ideation Attributes Scale [75] \\
\hline 11. & Tobacco, alcohol, and substance use & $\begin{array}{l}\text { Items adapted from the Alcohol Use Disorders Identification Test [76], the Alcohol, Smoking } \\
\text { and Substance Involvement Screening Test [77], the Cutting down, Annoyance by criticism, } \\
\text { Guilty feeling, and Eye-openers questionnaire [78], the Drinking Motives Questionnaire [79], } \\
\text { the Fagerström Test for Nicotine Dependence [80], and selected items from the National Drug } \\
\text { Strategy Household Survey [81] }\end{array}$ \\
\hline 12. & Physical activity & International Physical Activity Questionnaire [82] \\
\hline 13. & Sleep behaviors & Sleep-related items from the QIDS-SR-16 \\
\hline 14. & General mental health conditions & National Comorbidity Survey Replication Adolescent Supplement [83] \\
\hline 15. & Overall heath and somatic distress & $\begin{array}{l}\text { Somatic and Psychological Health Report [84], self-perceived health status, and general body } \\
\text { measurements }\end{array}$ \\
\hline 16. & Medical, mental health, and family history & Multiple-choice questions \\
\hline 17. & Cognitive concerns and empathy & $\begin{array}{l}\text { Derived from the Subjective Scale to Investigate Cognition in Schizophrenia [85] and the empathy } \\
\text { quotient [86] }\end{array}$ \\
\hline 18. & Eating behaviors and body image & Derived from the Eating Disorder Examination [87] \\
\hline 19. & Social connectedness and support & $\begin{array}{l}\text { Derived from the Perceived Social Support/Conflict Measure [88] plus } 5 \text { items measuring rela- } \\
\text { tionships with peers [89] }\end{array}$ \\
\hline
\end{tabular}

${ }^{\mathrm{a}} \mathrm{MHeC}-\mathrm{S}$ : Spanish version of the Mental Health eClinic.

${ }^{b}$ PTSD: posttraumatic stress disorder.

We didn't find any Spanish versions of the items assessing disability, suicide ideation, and anxiety rating. Considering their relevance in overall assessment and potential medicolegal repercussions, we decided to find Spanish-speaking analogs to these measures. We replaced the Brief Disability Questionnaire with the World Health Organization Disability Assessment Schedule 2.0, which has an official translation available [110]. We replaced the Suicidal Ideation Attributes Scale with the Suicide Behaviors Questionnaire-Revised [111] and we replaced the Overall Anxiety Severity and Impairment Scale with the 7-item Generalized Anxiety Disorder scale [112], both of which have their translation process and psychometric properties published.

In July 2016, the rest of the items were carefully translated into 3 individual sessions of colloquial Spanish, and we conducted 1 round of translation and cultural adaptation for Spanish-speaking populations living in Australia. At this stage, we adapted 3 questions in the demographics sections: country of origin; language spoken at home, enriched with relevant dialects from Spanish-speaking regions, such as Quichuan and Catalan; and the ethnicity question, modified to the indigenous populations in Latin America.

To reach agreement, 2 individual sessions of back-translations were performed, followed by 1 round of discussion between the translators and back-translators.

\section{User Interface}

All participants accepted the Spanish version of the original MHeC's logo (Figure 8). However, young people preferred a name that they could associate more with general well-being than with mental health, as some of them believed that this would have a wider reach among students.

In relation to language, participants expressed different preferences for the linguistic form in which to address the users (interlocutors); Colombian participants (20/32, 63\%) favored the use of formal pronouns (usted), as they considered that the 
delivery of online health services should follow the same conventions as face-to-face services:

In Colombia, the doctor-patient relationship is always treated in a formal way... [Health professional, quote O]

Participants of other nationalities (12/32, 38\%) preferred the prototype to use the colloquial or familiar pronouns (tú, vos), as the formal pronoun seemed excessively formal in an online context. Considering this discrepancy, all participants agreed that the prototype would use the colloquial or familiar form of the second person singular pronoun (tú), as the target of the $\mathrm{MHeC}-\mathrm{S}$ is young people from different nationalities. Additionally, participants suggested the possibility of a customizing option to choose to see the prototype (1) completely in Spanish (including menus, links, call-to-action buttons, instructions, videos, apps, and e-tools), (2) in a bilingual version (which would display menus, call-to-action buttons, and instructions in English, but the most relevant content in Spanish, such as the physical and mental health self-report assessment and video visit; or a mix of Spanish and English apps, e-tools, and resources), or (3) completely in English (which would look more like the original $\mathrm{MHeC}$ but with relevant information for this population).

Participants in the one-on-one user testing sessions $(n=15)$ assessed the interface in the prototype. These participants approved the MHeC-S's font, color palette (light blue, orange, and green), and the tile-shaped buttons $(15 / 15,100 \%)$. Despite this, young people $(7 / 15,47 \%)$ thought that the Get Started call-to-action button needed to be different (bolder, bigger, brighter, or in a different shape) to get the participants to sign up. In relation to the menus, horizontal or hamburger displays were preferred over the current vertical presentation.

Figure 8. Original Mental Health eClinic logo and its Spanish adaptation. Created by Mandarin Creative
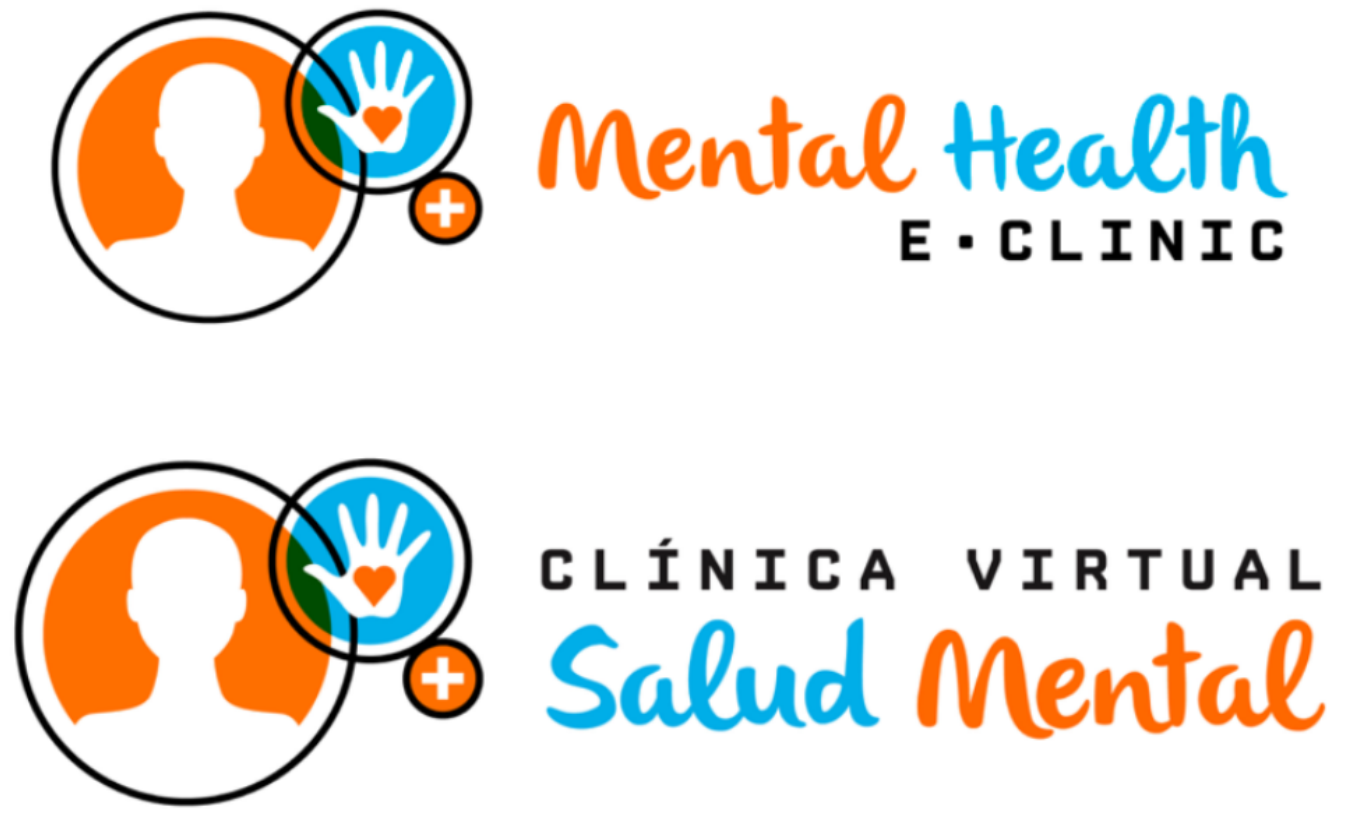

\section{Usability}

A total of 15 participants completed 4 usability tasks: (1) create an account and log in, (2) find the Need Help Now button, (3) explore the dashboard of results, and (4) book an appointment. Mean SEQ scores for the tasks were 7 (SD 0); 6.93 (SD 0.26); 5.07 (SD 1.49); 5.80 (1.66) respectively, range 1 to 7 . All 15 participants did not report problems completing tasks 1 and 2 . In relation to task 3, participants said that exploring all of the dashboard tabs was slightly complicated, as they were not evident at first glance. They had slight difficulty in completing an appointment booking, as the action button was located on the bottom right corner of the site, so this task wasn't intuitive for some participants.

\section{Discussion}

\section{Principal Findings}

Our study used a comprehensive research and development approach to co-design and culturally adapt a prototypic
Web-based mental health clinic $(\mathrm{MHeC})$ for Spanish-speaking young people based in Australia (MHeC-S). Thematic analysis resulted in adequate acceptability of the 5 main elements of the alpha prototype (a home page and triage system; a comprehensive online physical and mental health self-report assessment; a dashboard of results and progress report; a booking and videoconferencing system to enable video visits; and the generation of a personalized well-being plan that includes links to evidence-based, young person-suggested, health professional-recommended apps and e-tools). The data also revealed gaps in the alpha prototype, such as the need for tailored assessment tools and a greater integration with Spanish-speaking services and communities; a lack of Spanish-language apps and e-tools, and of online mental health information was noted. As a consequence, the development of new features included the addition of cultural adjustment items in the online self-report assessment, creation of specific algorithms, and development of several videos and factsheets (Multimedia Appendix 2). In the future, the beta prototype should additionally include refinements of language; 
explanations of specific medical terminology; and minor changes in layout and navigation.

Migrants and newly arrived residents have been identified as populations who are difficult to recruit, and then to involve and maintain in research [113], yet this is a population in critical need of support. The research and development cycle that we employed in this study is an optimal methodology to engage, retain, and work more efficiently with hard-to-reach populations. We selected various participatory design methodologies to enhance the generation of new ideas and improve the feedback process. The nature of the research and development cycle and the use of diverse methodologies enabled the research to be conducted and completed in a time-efficient manner.

Previous research has highlighted the need to tailor HIT interventions beyond content and language, by including culture [39]. One of the strengths of this study was the incorporation of the cultural framework as a cornerstone of the research and development cycle. As a consequence, we obtained information about the participants' cultural preferences for the prototype's interface and functionality, as well as the development of culturally appropriate content and features. Performing data collection and analysis in the original language reduced the risk of losing relevant information (or meaning), and decreased research time and costs [114]. Other advantages of this study were the variety of origin of participants (Argentina, Chile, Colombia, Spain, and Venezuela) and the research team (Australia, Chile, Colombia, and Venezuela). Furthermore, this research united all relevant stakeholders (young people, supportive others, and health professionals) in a common goal of adapting this prototype to a population in need.

Although Spanish is the second most common language spoken worldwide and HIT is a growing field, Spanish-speaking populations (including migrants and those residing in low- and middle-income countries) are at risk of experiencing not only physical but also technological social health inequalities [115]. This body of research aims to breach this gap by creating a widely available $\mathrm{MHeC}-\mathrm{S}$ that works across devices. The participation of end users in the design process ensured that the prototype was accessible to individuals of varying literacy levels with a range of cultural differences. Furthermore, the MHeC-S has the potential to be configured and adapted for use in Spanish-speaking countries and in other multicultural countries with Spanish-speaking migrant populations.

\section{Implications}

International education in Australia has grown dramatically and is its third largest export industry, contributing Aus \$32.4 billion to the Australian economy [116]. It highlights a significant bilateral exchange (Aus $\$ 755$ million in 2012) between Latin
America and Australia, which is increasingly recognized as an important destination for the English education of Latin Americans [117]. In 2017, the Latin American Spanish-speaking international student population had reportedly increased to more than 21,000 [17]. Our study highlighted a critical concern in the community in relation to a shortage of mental health services targeting the well-being of these students. This is vital, as these students are at higher risk of developing adaptational problems and being socially and linguistically isolated [118]. Participants generally expressed a lack of understanding of the Australian health system, particularly service providers and insurance agencies, resulting in an important barrier for students' help-seeking process. Even for those who do know how to navigate the health system, a reduced English competence could impair the care they do obtain. Protecting, caring for, and enhancing positive experiences for international students is Australia's best strategy to protect and grow this industry.

New and emerging technologies present a solution, as they have changed the way young people communicate, connect, and engage with each other and with society. With the introduction of smartphones, information, services, and resources provided online or via mobile apps can be accessed privately and at any time. This can be empowering for individuals who are marginalized or geographically or socially isolated. It could also help to address the need for Spanish-speaking mental health professionals and interpreters. Having an $\mathrm{MHeC}-\mathrm{S}$ could greatly benefit young people who are native Spanish speakers living in Australia and who are actively seeking help. This study is the first step toward providing a technology-enabled solution to improve this population's mental health and well-being in Australia. To the best of our knowledge, there has been no research to date in this field.

\section{Conclusion}

Further research is needed to understand the psychometric properties of the online self-report assessment (eg, criterion validity) and the integration of the $\mathrm{MHeC}-\mathrm{S}$ with other apps or e-tools. Importantly, additional steps are needed to evaluate the engagement, efficacy, and effectiveness of the MHeC-S in real-world settings. The $\mathrm{MHeC}-\mathrm{S}$ shares the same elements and functionality of the original version of the $\mathrm{MHeC}$. Its main difference relies on interaction with face-to-face services. The original $\mathrm{MHeC}$ was designed to work with primary care mental health services; however, in the case of the $\mathrm{MHeC}-\mathrm{S}$, in Australia it could be used additionally by language schools and Overseas Student Health Cover providers. To the best of our knowledge, this study is the first to explore mental health care barriers and facilitators, and potential technology solutions in a language student population; additional research is needed to expand the knowledge on this topic.

\section{Acknowledgments}

The authors would like to thank all young people, supportive others, and health professionals who participated in this study. Additionally, we thank headspace Campbelltown, headspace Camperdown, the Consulate General of Colombia in Sydney, Ms Nancy Benitez Paez (Consul General of Colombia in Sydney), Dr Andres Rangel Martinez-Villalba, Dr German Rueda-Jaimes, and Dr Carlos Filizzola Donado for their collaboration in this study. We would also like to thank Ms Javiera Gálvez and Ms Camila Bravo for their work translating the content of the prototype; Ms Lauren Cannell for her work in the translation and 
back-translation process; and Ms Abigail Escobar for coding the data. This project was funded by the Young and Well Cooperative Research Centre (Western Sydney University, Penrith, Australia; 2014-2016), which was led by Professor Jane Burns.

\section{Conflicts of Interest}

IBH was an inaugural Commissioner on Australia's National Mental Health Commission (2012-18). He is the Co-Director, Health and Policy at the Brain and Mind Centre (BMC) University of Sydney. The BMC operates early-intervention youth services at Camperdown under contract to headspace. IBH is the Chief Scientific Advisor to, and a 5\% equity shareholder in, InnoWell Pty Ltd. InnoWell was formed by the University of Sydney (45\% equity) and PwC (Australia; $45 \%$ equity) to deliver the $\$ 30 \mathrm{M}$ Australian Government Department of Health-funded Project Synergy (2017-20); a three-year program for the transformation of mental health services) and to lead transformation of mental health services internationally through the use of innovative technologies

\section{Multimedia Appendix 1}

Original quotes in Spanish.

[PDF File (Adobe PDF File), 47KB-Multimedia Appendix 1]

\section{Multimedia Appendix 2}

Development of new features during the rapid prototyping phase.

[PDF File (Adobe PDF File), 30KB-Multimedia Appendix 2]

\section{References}

1. World Health Organization. Mental Health Atlas 2017. Geneva, Switzerland: WHO; 2018. URL: https://apps.who.int/iris/ bitstream/handle/10665/272735/9789241514019-eng.pdf [accessed 2019-06-20]

2. Clarke G, Yarborough BJ. Evaluating the promise of health IT to enhance/expand the reach of mental health services. Gen Hosp Psychiatry 2013;35(4):339-344 [FREE Full text] [doi: 10.1016/j.genhosppsych.2013.03.013] [Medline: 23701698]

3. Gore FM, Bloem PJN, Patton GC, Ferguson J, Joseph V, Coffey C, et al. Global burden of disease in young people aged 10-24 years: a systematic analysis. Lancet 2011 Jun 18;377(9783):2093-2102. [doi: 10.1016/S0140-6736(11)60512-6] [Medline: 21652063]

4. Patel V, Maj M, Flisher AJ, De Silva MJ, Koschorke M, Prince M, WPA Zonal and Member Society Representatives. Reducing the treatment gap for mental disorders: a WPA survey. World Psychiatry 2010 Oct;9(3):169-176 [FREE Full text] [Medline: 20975864]

5. Ohtani A, Suzuki T, Takeuchi H, Uchida H. Language barriers and access to psychiatric care: a systematic review. Psychiatr Serv 2015 Aug 01;66(8):798-805. [doi: 10.1176/appi.ps.201400351] [Medline: 25930043]

6. Kim E, Coumar A, Lober WB, Kim Y. Addressing mental health epidemic among university students via web-based, self-screening, and referral system: a preliminary study. IEEE Trans Inf Technol Biomed 2011 Mar;15(2):301-307. [doi: 10.1109/TITB.2011.2107561] [Medline: 21257386]

7. Blignault I, Ponzio V, Rong Y, Eisenbruch M. A qualitative study of barriers to mental health services utilisation among migrants from mainland China in south-east Sydney. Int J Soc Psychiatry 2008 Mar;54(2):180-190. [doi: 10.1177/0020764007085872] [Medline: 18488410]

8. Kelaher M, Williams G, Manderson L. Towards evidence-based health promotion and service provision for new migrants to Australia. Ethn Health 1999 Nov;4(4):305-313. [doi: 10.1080/13557859998074] [Medline: 10705566]

9. Studies in Australia. International students in Australia. Melbourne, Australia: Good Education Group Pty Ltd; 2019. URL: https://www.studiesinaustralia.com/studying-in-australia/why-study-in-australia/international-students-in-australia[WebCite Cache ID 76KbPEmLW]

10. Bhugra D. Migration and mental health. Acta Psychiatr Scand 2004 Apr;109(4):243-258. [Medline: 15008797]

11. Suh H, van Nuenen M, Rice KG. The CES-D as a measure of psychological distress among international students: measurement and structural invariance across gender. Assessment 2017 Oct;24(7):896-906. [doi: 10.1177/1073191116632337] [Medline: 26887810]

12. Lee RB, Maria MS, Estanislao S, Rodriguez C. Factors associated with higher levels of depressive symptoms among international university students in the Philippines. Southeast Asian J Trop Med Public Health 2013 Nov;44(6):1098-1107. [Medline: 24450248]

13. Khawaja NG, Dempsey J. A comparison of international and domestic tertiary students in Australia. J Psychol Couns Sch 2008;18(1):30-46.

14. Forbes-Mewett H, Sawyer AM. Mental Health Issues Amongst International Students in Australia: Perspectives From Professionals at the Coal-Face. Callaghan, Australia: University of Newcastle; 2011. 
15. Pejic D. International Student Welfare in Australia. Melbourne, Australia: International Social Service Australia; 2012. URL: http://www.iss.org.au/wp-content/uploads/2012/07/International-Student-Welfare-in-Australia.pdf]WebCite Cache ID $706 \mathrm{gGEzJe}]$

16. Kwan B. Mental health stigma biggest barrier for international students seeking help. Crows Nest, Australia: SBSNews; 2019. URL: https://www.sbs.com.au/news/ mental-health-stigma-biggest-barrier-for-international-students-seeking-help[WebCite Cache ID 76hIjeSD9]

17. Australian Government Department of Home Affairs. Student visa and Temporary Graduate visa program bi-annual report. Canberra, Australia: The Department; 2017. URL: https:/www.homeaffairs.gov.au/research-and-stats/files/ student-temp-grad-program-report-dec-2018.pdf[WebCite Cache ID 76kRHhjHy]

18. McHugh RK, Barlow DH. The dissemination and implementation of evidence-based psychological treatments. A review of current efforts. Am Psychol 2010;65(2):73-84. [doi: 10.1037/a0018121] [Medline: 20141263]

19. Judd FK, Jackson H, Davis J, Cockram A, Komiti A, Allen N, et al. Improving access for rural Australians to treatment for anxiety and depression: the University of Melbourne Depression and Anxiety Research and Treatment Group-Bendigo Health Care Group initiative. Aust J Rural Health 2001 Apr;9(2):91-96. [Medline: 11259963]

20. Blaya JA, Fraser HSF, Holt B. E-health technologies show promise in developing countries. Health Aff (Millwood) 2010 Feb;29(2):244-251 [FREE Full text] [doi: 10.1377/hlthaff.2009.0894] [Medline: 20348068]

21. Hoek W, Marko M, Fogel J, Schuurmans J, Gladstone T, Bradford N, et al. Randomized controlled trial of primary care physician motivational interviewing versus brief advice to engage adolescents with an Internet-based depression prevention intervention: 6-month outcomes and predictors of improvement. Transl Res $2011 \mathrm{Dec} ; 158(6): 315-325$. [doi: 10.1016/j.trsl.2011.07.006] [Medline: 22061038]

22. van der Zanden R, Kramer J, Gerrits R, Cuijpers P. Effectiveness of an online group course for depression in adolescents and young adults: a randomized trial. J Med Internet Res 2012;14(3):e86 [FREE Full text] [doi: 10.2196/jmir.2033] [Medline: 22677437]

23. Tait RJ, Christensen H. Internet-based interventions for young people with problematic substance use: a systematic review. Med J Aust 2010 Jun 7;192(11 Suppl):S15-S21. [Medline: 20528701]

24. Calear AL, Christensen H. Review of internet-based prevention and treatment programs for anxiety and depression in children and adolescents. Med J Aust 2010 Jun 7;192(11 Suppl):S12-S14. [Medline: 20528700]

25. Hunkeler EM, Meresman JF, Hargreaves WA, Fireman B, Berman WH, Kirsch AJ, et al. Efficacy of nurse telehealth care and peer support in augmenting treatment of depression in primary care. Arch Fam Med 2000 Aug;9(8):700-708. [Medline: 10927707]

26. Epstein JN, Langberg JM, Lichtenstein PK, Kolb R, Altaye M, Simon JO. Use of an internet portal to improve community-based pediatric ADHD care: a cluster randomized trial. Pediatrics 2011 Nov;128(5):e1201-e1208 [FREE Full text] [doi: 10.1542/peds.2011-0872] [Medline: 22007005]

27. Mitchell J, Vella-Brodrick D, Klein B. Positive psychology and the internet: a mental health opportunity. E J Appl Psychol 2010 Dec 30;6(2):30-41. [doi: 10.7790/ejap.v6i2.230]

28. van Straten SA, Seekles W, van't Veer-Tazelaar NJ, Beekman ATF, Cuijpers P. Stepped care for depression in primary care: what should be offered and how? Med J Aust 2010 Jun 7;192(11 Suppl):S36-S39. [Medline: 20528706]

29. Perini S, Titov N, Andrews G. Clinician-assisted Internet-based treatment is effective for depression: randomized controlled trial. Aust N Z J Psychiatry 2009 Jun;43(6):571-578. [doi: 10.1080/00048670902873722] [Medline: 19440890]

30. Saulsberry A, Marko-Holguin M, Blomeke K, Hinkle C, Fogel J, Gladstone T, et al. Randomized clinical trial of a primary care internet-based intervention to prevent adolescent depression: one-year outcomes. J Can Acad Child Adolesc Psychiatry 2013 May;22(2):106-117 [FREE Full text] [Medline: 23667356]

31. Martínez P, Rojas G, Martínez V, Lara MA, Pérez JC. Internet-based interventions for the prevention and treatment of depression in people living in developing countries: a systematic review. J Affect Disord 2018 Dec;234:193-200. [doi: 10.1016/j.jad.2018.02.079] [Medline: 29529553]

32. Saliba V, Legido-Quigley H, Hallik R, Aaviksoo A, Car J, McKee M. Telemedicine across borders: a systematic review of factors that hinder or support implementation. Int J Med Inform 2012 Dec;81(12):793-809. [doi: 10.1016/j.ijmedinf.2012.08.003] [Medline: 22975018]

33. Barrera-Valencia C, Benito-Devia AV, Vélez-Álvarez C, Figueroa-Barrera M, Franco-Idárraga SM. [Cost-effectiveness of synchronous vs. asynchronous telepsychiatry in prison inmates with depression]. Rev Colomb Psiquiatr 2017;46(2):65-73. [doi: 10.1016/j.rcp.2016.04.008] [Medline: 28483175]

34. Castro A, Larraín A, Fritsch R, Rojas G. [Feasibility of implementing tele-psychiatry in Chile]. Rev Med Chil 2012 Jun;140(6):789-796 [FREE Full text] [doi: 10.4067/S0034-98872012000600015] [Medline: 23282619]

35. Moreno FA, Chong J, Dumbauld J, Humke M, Byreddy S. Use of standard webcam and internet equipment for telepsychiatry treatment of depression among underserved Hispanics. Psychiatr Serv 2012 Dec;63(12):1213-1217. [doi:

10.1176/appi.ps.201100274] [Medline: 23026854]

36. Baker-Ericzén MJ, Connelly CD, Hazen AL, Dueñas C, Landsverk JA, Horwitz SM. A collaborative care telemedicine intervention to overcome treatment barriers for Latina women with depression during the perinatal period. Fam Syst Health 2012 Sep;30(3):224-240 [FREE Full text] [doi: 10.1037/a0028750] [Medline: 22709321] 
37. Mucic D. International telepsychiatry: a study of patient acceptability. J Telemed Telecare 2008;14(5):241-243. [doi: 10.1258/jtt.2008.080301] [Medline: 18632998]

38. Yellowlees PM, Odor A, Iosif A, Parish MB, Nafiz N, Patrice K, et al. Transcultural psychiatry made simple--asynchronous telepsychiatry as an approach to providing culturally relevant care. Telemed J E Health 2013 Apr;19(4):259-264 [FREE Full text] [doi: 10.1089/tmj.2012.0077] [Medline: 23451812]

39. Chaet AV, Morshedi B, Wells KJ, Barnes LE, Valdez R. Spanish-language consumer health information technology interventions: a systematic review. J Med Internet Res 2016 Dec 10;18(8):e214 [FREE Full text] [doi: 10.2196/jmir.5794] [Medline: 27511437]

40. Ferrari M, Ahmad F, Shakya Y, Ledwos C, McKenzie K. Computer-assisted client assessment survey for mental health: patient and health provider perspectives. BMC Health Serv Res 2016 Sep 23;16(1):516 [FREE Full text] [doi: 10.1186/s12913-016-1756-0] [Medline: 27663508]

41. Aguilera A, Bruehlman-Senecal E, Demasi O, Avila P. Automated text messaging as an adjunct to cognitive behavioral therapy for depression: a clinical trial. J Med Internet Res 2017 May 08;19(5):e148 [FREE Full text] [doi: 10.2196/jmir.6914] [Medline: 28483742]

42. Romero-Sanchiz P, Nogueira-Arjona R, García-Ruiz A, Luciano JV, García CJ, Gili M, et al. Economic evaluation of a guided and unguided internet-based CBT intervention for major depression: results from a multi-center, three-armed randomized controlled trial conducted in primary care. PLoS One 2017;12(2):e0172741 [FREE Full text] [doi: 10.1371/journal.pone.0172741] [Medline: 28241025]

43. Ramos K, Cortes J, Wilson N, Kunik ME, Stanley MA. Vida Calma: CBT for anxiety with a Spanish-speaking Hispanic adult. Clin Gerontol 2017;40(3):213-219. [doi: 10.1080/07317115.2017.1292978] [Medline: 28452668]

44. Muroff J, Robinson W, Chassler D, López LM, Gaitan E, Lundgren L, et al. Use of a smartphone recovery tool for Latinos with co-occurring alcohol and other drug disorders and mental disorders. J Dual Diagn 2017;13(4):280-290. [doi: 10.1080/15504263.2017.1348649] [Medline: 28692420]

45. Bjerkan J, Hedlund M, Helles $\emptyset$ R. Patients' contribution to the development of a web-based plan for integrated care - a participatory design study. Inform Health Soc Care 2015 Mar;40(2):167-184. [doi: 10.3109/17538157.2014.907803] [Medline: 24786524]

46. Peters D, Davis S, Calvo RA, Sawyer SM, Smith L, Foster JM. Young people's preferences for an asthma self-management app highlight psychological needs: a participatory study. J Med Internet Res 2017 Apr 11;19(4):e113 [FREE Full text] [doi: 10.2196/jmir.6994] [Medline: 28400353]

47. Petersen C, Adams SA, DeMuro PR. mHealth: don't forget all the stakeholders in the business case. Med 2.02015 Dec 31;4(2):e4 [FREE Full text] [doi: 10.2196/med20.4349] [Medline: 26720310]

48. Ospina-Pinillos L, Davenport T, Iorfino F, Tickell A, Cross S, Scott EM, et al. Using new and innovative technologies to assess clinical stage in early intervention youth mental health services: evaluation study. J Med Internet Res 2018 Sep 10;20(9):e259 [FREE Full text] [doi: 10.2196/jmir.9966] [Medline: 30201602]

49. Ginossar T, Nelson S. Reducing the health and digital divides: a model for using community-based participatory research approach to e-health interventions in low-income Hispanic communities. J Comput Mediat Commun 2010;15(4):a. [doi: 10.1111/j.1083-6101.2009.01513.x]

50. Hickie IB, Luscombe GM, Davenport TA, Burns JM, Highet NJ. Perspectives of young people on depression: awareness, experiences, attitudes and treatment preferences. Early Interv Psychiatry 2007 Nov;1(4):333-339. [doi: 10.1111/j.1751-7893.2007.00042.x] [Medline: 21352121]

51. Hickie IB, McGorry PD. Guidelines for youth depression: time to incorporate new perspectives. Med J Aust 2010 Aug 02;193(3):133-134. [Medline: 20678036]

52. Christensen H, Petrie K. State of the e-mental health field in Australia: where are we now? Aust N Z J Psychiatry 2013 Feb;47(2):117-120. [doi: 10.1177/0004867412471439] [Medline: 23297367]

53. Ospina-Pinillos L, Davenport TA, Ricci CS, Milton AC, Scott EM, Hickie IB. Developing a Mental Health eClinic to improve access to and quality of mental health care for young people: using participatory design as research methodologies. J Med Internet Res 2018 May 28;20(5):e188 [FREE Full text] [doi: 10.2196/jmir.9716] [Medline: 29807878]

54. Hagen P, Collin P, Metcalf A, Nicholas M, Rahilly K, Swainston N. Participatory Design of Evidence-Based Online Youth Mental Health Promotion, Intervention and Treatment. Melbourne, Australia: Young and Well Cooperative Research Centre; 2012:978.

55. Sousa VD, Rojjanasrirat W. Translation, adaptation and validation of instruments or scales for use in cross-cultural health care research: a clear and user-friendly guideline. J Eval Clin Pract 2011 Apr;17(2):268-274. [doi:

10.1111/j.1365-2753.2010.01434.x] [Medline: 20874835]

56. Boren T, Ramey J. Thinking aloud: reconciling theory and practice. IEEE Trans Profess Commun 2000;43(3):261-278. [doi: $10.1109 / 47.867942]$

57. Sauro J. 10 things to know about the Single Ease Question (SEQ). Denver, CO: Measuring U; 2012. URL: https://measuringu. com/seq10/[WebCite Cache ID 6vcXt6iSr]

58. Braun V, Clarke V. Using thematic analysis in psychology. Qual Res Psychol 2006 Jan;3(2):77-101. [doi: 10.1191/1478088706qp063oa] 
59. Hoover RS, Koerber AL. Using NVivo to answer the challenges of qualitative research in professional communication: benefits and best practices tutorial. IEEE Trans Profess Commun 2011 Mar;54(1):68-82. [doi: 10.1109/TPC.2009.2036896]

60. Valdez RS, Gibbons MC, Siegel ER, Kukafka R, Brennan PF. Designing consumer health IT to enhance usability among different racial and ethnic groups within the United States. Health Technol 2012 Jul 13;2(4):225-233. [doi: $10.1007 / \mathrm{s} 12553-012-0031-6]$

61. Pope C, Ziebland S, Mays N. Qualitative research in health care. Analysing qualitative data. BMJ 2000 Jan 8;320(7227):114-116 [FREE Full text] [Medline: 10625273]

62. Davey JW, Gugiu PC, Coryn CL. Quantitative methods for estimating the reliability of qualitative data. J Multidiscipl Eval 2010;6(13):140-162.

63. Viera AJ, Garrett JM. Understanding interobserver agreement: the kappa statistic. Fam Med 2005 May;37(5):360-363 [FREE Full text] [Medline: 15883903]

64. Milton AC, Ellis LA, Davenport TA, Burns JM, Hickie IB. Comparison of self-reported telephone interviewing and web-based survey responses: findings from the Second Australian Young and Well National Survey. JMIR Ment Health 2017 Sep 26;4(3):e37. [doi: 10.2196/mental.8222] [Medline: 28951382]

65. Tate CC, Ledbetter JN, Youssef CP. A two-question method for assessing gender categories in the social and medical sciences. J Sex Res 2013;50(8):767-776. [doi: 10.1080/00224499.2012.690110] [Medline: 22989000]

66. Ormel J, VonKorff M, Ustun TB, Pini S, Korten A, Oldehinkel T. Common mental disorders and disability across cultures. Results from the WHO Collaborative Study on Psychological Problems in General Health Care. JAMA 1994 Dec 14;272(22):1741-1748. [Medline: 7966922]

67. Goldman HH, Skodol AE, Lave TR. Revising axis V for DSM-IV: a review of measures of social functioning. Am J Psychiatry 1992 Sep;149(9):1148-1156. [Medline: 1386964$]$

68. Kessler RC, Andrews G, Colpe LJ, Hiripi E, Mroczek DK, Normand SLT, et al. Short screening scales to monitor population prevalences and trends in non-specific psychological distress. Psychol Med 2002 Aug;32(6):959-976. [Medline: 12214795]

69. Rush AJ, Trivedi MH, Ibrahim HM, Carmody TJ, Arnow B, Klein DN, et al. The 16-Item Quick Inventory of Depressive Symptomatology (QIDS), clinician rating (QIDS-C), and self-report (QIDS-SR): a psychometric evaluation in patients with chronic major depression. Biol Psychiatry 2003 Sep 01;54(5):573-583. [Medline: 12946886]

70. Norman SB, Cissell SH, Means-Christensen AJ, Stein MB. Development and validation of an Overall Anxiety Severity And Impairment Scale (OASIS). Depress Anxiety 2006;23(4):245-249. [doi: 10.1002/da.20182] [Medline: 16688739]

71. Altman EG, Hedeker D, Peterson JL, Davis JM. The Altman Self-Rating Mania Scale. Biol Psychiatry 1997 Nov 15;42(10):948-955. [doi: 10.1016/S0006-3223(96)00548-3] [Medline: 9359982]

72. Stefanis NC, Hanssen M, Smirnis NK, Avramopoulos DA, Evdokimidis IK, Stefanis CN, et al. Evidence that three dimensions of psychosis have a distribution in the general population. Psychol Med 2002 Feb;32(2):347-358. [Medline: 11866327]

73. Prins A, Ouimette P, Kimerling R, Camerond RP, Hugelshofer DS, Shaw-Hegwer J, et al. The primary care PTSD screen (PC-PTSD): development and operating characteristics. Prim Care Psychiatry 2004 Jan 01;9(1):9-14. [doi:

10.1185/135525703125002360]

74. Blanchard EB, Jones-Alexander J, Buckley TC, Forneris CA. Psychometric properties of the PTSD Checklist (PCL). Behav Res Ther 1996 Aug;34(8):669-673. [Medline: 8870294]

75. van Spijker BAJ, Batterham PJ, Calear AL, Farrer L, Christensen H, Reynolds J, et al. The suicidal ideation attributes scale (SIDAS): community-based validation study of a new scale for the measurement of suicidal ideation. Suicide Life Threat Behav 2014 Aug;44(4):408-419. [doi: 10.1111/sltb.12084] [Medline: 24612048]

76. Saunders JB, Aasland OG, Babor TF, de la Fuente JR, Grant M. Development of the Alcohol Use Disorders Identification Test (AUDIT): WHO Collaborative Project on Early Detection of Persons with Harmful Alcohol Consumption--II. Addiction 1993 Jun;88(6):791-804. [Medline: 8329970]

77. WHO ASSIST Working Group. The Alcohol, Smoking and Substance Involvement Screening Test (ASSIST): development, reliability and feasibility. Addiction 2002 Sep;97(9):1183-1194. [Medline: 12199834]

78. Ewing JA. Detecting alcoholism. The CAGE questionnaire. JAMA 1984 Oct 12;252(14):1905-1907. [Medline: 6471323]

79. Cooper ML. Motivations for alcohol use among adolescents: development and validation of a four-factor model. Psychol Assess 1994;6(2):117-128. [doi: 10.1037/1040-3590.6.2.117]

80. Heatherton TF, Kozlowski LT, Frecker RC, Fagerström KO. The Fagerström Test for Nicotine Dependence: a revision of the Fagerström Tolerance Questionnaire. Br J Addict 1991 Sep;86(9):1119-1127. [Medline: 1932883]

81. Australian Institute of Health and Welfare. National Drug Strategy Household Survey: detailed report 2013. Canberra, Australia: AIHW; 2014. URL: https://www.aihw.gov.au/getmedia/c2e94ca2-7ce8-496f-a765-94c55c774d2b/16835_1.pdf. aspx?inline=true

82. Craig CL, Marshall AL, Sjöström M, Bauman AE, Booth ML, Ainsworth BE, et al. International physical activity questionnaire: 12-country reliability and validity. Med Sci Sports Exerc 2003 Aug;35(8):1381-1395. [doi: 10.1249/01.MSS.0000078924.61453.FB] [Medline: 12900694]

83. Green JG, Avenevoli S, Gruber MJ, Kessler RC, Lakoma MD, Merikangas KR, et al. Validation of diagnoses of distress disorders in the US National Comorbidity Survey Replication Adolescent Supplement (NCS-A). Int J Methods Psychiatr Res 2012 Mar;21(1):41-51 [FREE Full text] [doi: 10.1002/mpr.357] [Medline: 22086845] 
84. Hickie IB, Davenport TA, Hadzi-Pavlovic D, Koschera A, Naismith SL, Scott EM, et al. Development of a simple screening tool for common mental disorders in general practice. Med J Aust 2001 Jul 16;175 Suppl:S10-S17. [Medline: 11556430$]$

85. Stip E, Caron J, Renaud S, Pampoulova T, Lecomte Y. Exploring cognitive complaints in schizophrenia: the subjective scale to investigate cognition in schizophrenia. Compr Psychiatry 2003;44(4):331-340. [doi:

10.1016/S0010-440X(03)00086-5] [Medline: 12923712]

86. Muncer SJ, Ling J. Psychometric analysis of the empathy quotient (EQ) scale. Pers Indiv Diff 2006 Apr;40(6):1111-1119. [doi: 10.1016/j.paid.2005.09.020]

87. Hay P. The epidemiology of eating disorder behaviors: an Australian community-based survey. Int J Eat Disord 1998 May;23(4):371-382. [Medline: 9561427]

88. Schuster TL, Kessler RC, Aseltine RH. Supportive interactions, negative interactions, and depressed mood. Am J Community Psychol 1990 Jun;18(3):423-438. [Medline: 2264558]

89. Catholic Education Commission, New South Wales. Guidelines for Pastoral Care in Catholic Schools. Canberra, Australia: Commonwealth Department of Education, Science and Training; 2003. URL: http://www.cecnsw.catholic.edu.au/images/ Guidelines\%20for\%20Pastoral\%20Care\%20In\%20Catholic\%20Schools.pdf[WebCite Cache ID 6woyDiVoh]

90. Reisner SL, Biello K, Rosenberger JG, Austin SB, Haneuse S, Perez-Brumer A, et al. Using a two-step method to measure transgender identity in Latin America/the Caribbean, Portugal, and Spain. Arch Sex Behav 2014 Nov;43(8):1503-1514 [FREE Full text] [doi: 10.1007/s10508-014-0314-2] [Medline: 25030120]

91. [National Comorbidity Survey. K10 and K6 scales].: World Health Organization; 2006. URL: https://www. hcp.med.harvard.edu/ncs/ftpdir/k6/Spanish_K10.pdf[WebCite Cache ID 6v9fXhI8g]

92. Trujols J, de Diego-Adeliño J, Feliu-Soler A, Iraurgi I, Puigdemont D, Alvarez E, et al. The Spanish version of the Quick Inventory of Depressive Symptomatology-Self-Report (QIDS-SR16): a psychometric analysis in a clinical sample. J Affect Disord 2014 Dec;169:189-196. [doi: 10.1016/j.jad.2014.08.011] [Medline: 25212994]

93. Gili M, Lopez-Navarro E, Homar C, Castro A, García-Toro M, Llobera J, et al. Psychometric properties of Spanish version of QIDS-SR16 in depressive patients. Actas Esp Psiquiatr 2014;42(6):292-299 [FREE Full text] [Medline: 25388771]

94. van Os J, Verdoux H, Hanssen M. CAPE 42. 2001. URL: http://cape42.homestead.com/[WebCite Cache ID 6v9hNwcwd]

95. Fonseca-Pedrero E, Paino M, Lemos-Giráldez S, Muñiz J. Validation of the Community Assessment Psychic Experiences -42 (CAPE-42) in Spanish college students and patients with psychosis. Actas Esp Psiquiatr 2012;40(4):169-176 [FREE Full text] [Medline: 22851477]

96. Babor T, Higgins-Biddle J. Intervención breve para el consumo de riesgo y perjudicial de alcohol. Geneva, Switzerland: World Health Organization; 2001. URL: http://www.who.int/substance abuse/activities/en/BImanualSpanish.pdf $[$ WebCite Cache ID 6vArKNVap]

97. World Health Organization. La prueba de detección de consumo de alcohol, tabaco y sustancias (ASSIST). Manual para uso en la atención primaria. Geneva, Switzerland: WHO; 2011.

98. The IPAQ Group. International Physical Activity Questionnaire. 2016. URL: https://sites.google.com/site/theipaq/ home[WebCite Cache ID 6vBDlmCVX]

99. The IPAQ Group. IPAQ: formato corto autoadministrado de los últimos 7 días. 2002 Aug. URL: https://docs.google.com/ viewer? $\mathrm{a}=\mathrm{v} \&$ pid=sites\&srcid=ZGVmYXVsdGRvbWFpbnx0aGVpcGFxfGd4OjJhOTZhOGFhMWNjNzI0NTI[WebCite Cache ID 6vBDTBbaA]

100. Medina-Mora ME, Borges G, Lara C, Benjet C, Blanco J, Fleiz C, et al. Prevalence, service use, and demographic correlates of 12-month DSM-IV psychiatric disorders in Mexico: results from the Mexican National Comorbidity Survey. Psychol Med 2005 Dec;35(12):1773-1783. [doi: 10.1017/S0033291705005672] [Medline: 16300691]

101. Benjet C, Borges G, Medina-Mora ME, Zambrano J, Aguilar-Gaxiola S. Youth mental health in a populous city of the developing world: results from the Mexican Adolescent Mental Health Survey. J Child Psychol Psychiatry 2009 Apr;50(4):386-395. [doi: 10.1111/j.1469-7610.2008.01962.x] [Medline: 19040499]

102. Rendon MJ. The Cultural Adaptation of the Clinician-Administered PTSD Scale for Spanish-Speaking Latinos With Limited English Proficiency in the United States [doctoral thesis]. Coral Gables, FL: University of Miami; 2015. URL: https:/ /scholarlyrepository.miami.edu/cgi/viewcontent.cgi?article=2540\&context=oa dissertations [WebCite Cache ID 777PL8n5q]

103. Miles JNV, Marshall GN, Schell TL. Spanish and English versions of the PTSD Checklist-Civilian version (PCL-C): testing for differential item functioning. J Trauma Stress 2008 Aug;21(4):369-376 [FREE Full text] [doi: 10.1002/jts.20349] [Medline: 18720394$]$

104. Alvarez Mas P, Benavent Rodríguez P, García Valls JM, Livianos Aldana L, Rojo Moreno L. [Translation and adaptation in the Spanish environment of the Altman Self-Rating Mania Scale]. Actas Esp Psiquiatr 2005;33(3):180-187. [Medline: $\underline{15918086]}$

105. Ferreira Gonzalez L. Cuestionario CAGE: screening de alcoholismo. URL: http://meiga.info/escalas/cuestionariocage. pdf[WebCite Cache ID 6vAtlYltq]

106. Confederación Española de Organizaciones Empresariales. Test Audit y CAGE. 2011. URL: http://contenidos.ceoe.es/PRL/ var/pool/pdf/cms content documents-file-767-test-audit-y-cage.pdf[WebCite Cache ID 6v0KkwZaV]

107. Campo-Arias A, Barros-Bermúdez J, Rueda-Jaimes G. Propiedades psicométricas del cuestionario CAGE para consumo abusivo de alcohol: resultados de tres análisis. Rev Colombiana Psiquiatr 2009;38(2):294-303. 
108. Becoña E, Vázquez FL. The Fagerström Test for Nicotine Dependence in a Spanish sample. Psychol Rep 1998 Dec;83(3 Pt 2):1455-1458. [doi: $10.2466 / p r 0.1998 .83 .3 f .1455]$ [Medline: 10079737 ]

109. Autism Research Centre. Downloadable tests. Cambridge, UK: University of Cambridge; 2017. URL: https://www. autismresearchcentre.com/arc tests[WebCite Cache ID 6vBJtDZyb]

110. World Health Organization. Medición de la Salud y la Discapacidad, Manual para el Cuestionario de Evaluación de la Discapacidad de la OMS. WHODAS 2.0. Geneva, Switzerland: WHO; 2015:89.

111. Rueda-Jaimes G, Castro-Rueda V, Rangel-Martínez-Villalba A, Corzo-Casasadiego J, Moreno-Quijano C, Camacho P. Validity of the Suicide Behaviors Questionnaire-Revised in patients with short-term suicide risk. Eur J Psychiatry 2017;31(4):145-150. [doi: 10.1016/j.ejpsy.2017.09.002]

112. García-Campayo J, Zamorano E, Ruiz MA, Pardo A, Pérez-Páramo M, López-Gómez V, et al. Cultural adaptation into Spanish of the generalized anxiety disorder-7 (GAD-7) scale as a screening tool. Health Qual Life Outcomes 2010 Jan 20;8:8 [FREE Full text] [doi: 10.1186/1477-7525-8-8] [Medline: 20089179]

113. Shaghaghi A, Bhopal RS, Sheikh A. Approaches to recruiting 'hard-to-reach' populations into research: a review of the literature. Health Promot Perspect 2011;1(2):86-94 [FREE Full text] [doi: 10.5681/hpp.2011.009] [Medline: 24688904]

114. Smith HJ, Chen J, Liu X. Language and rigour in qualitative research: problems and principles in analyzing data collected in Mandarin. BMC Med Res Methodol 2008 Jul 10;8:44 [FREE Full text] [doi: 10.1186/1471-2288-8-44] [Medline: $\underline{18616812]}$

115. Latulippe K, Hamel C, Giroux D. Social health inequalities and eHealth: a literature review with qualitative synthesis of theoretical and empirical studies. J Med Internet Res 2017 Apr 27;19(4):e136 [FREE Full text] [doi: 10.2196/jmir.6731] [Medline: 28450271]

116. Australian Government Department of Education and Training. Research snapshot: 2017-18 export income by state and territory. 2018 Dec. URL: https://internationaleducation.gov.au/research/Research-Snapshots/Documents/ Education\%20infographic\%20Australia\%202017\%E2\%80\%9318.pdf [WebCite Cache ID 76kO4kvRa]

117. Carr B, Minns J. Australia and Latin America: Challenges and Opportunities in the New Millennium. Canberra, Australia: ANU Press; 2014.

118. Demes KA, Geeraert N. Measures matter: scales for adaptation, cultural distance, and acculturation orientation revisited. J Cross Cult Psychol 2013 Jun 11;45(1):91-109. [doi: 10.1177/0022022113487590]

\author{
Abbreviations \\ HIT: health information technology \\ MHeC: Mental Health eClinic \\ MHeC-S: Spanish version of the Mental Health eClinic \\ NSW: New South Wales \\ PTSD: posttraumatic stress disorder \\ SEQ: Single Ease Question
}

Edited by G Eysenbach; submitted 27.03.19; peer-reviewed by N Miyoshi, A Nguyen; comments to author 30.05.19; revised version
received $11.06 .19 ;$ accepted 12.06.19; published 02.08.19
Please cite as:
Ospina-Pinillos L, Davenport T, Mendoza Diaz A, Navarro-Mancilla A, Scott EM, Hickie IB
Using Participatory Design Methodologies to Co-Design and Culturally Adapt the Spanish Version of the Mental Health eClinic:
Qualitative Study
J Med Internet Res 2019;21(8):e14127
URL: $\underline{\text { https://www.jmir.org/2019/8/e14127/ }}$
doi: $\underline{10.2196 / 14127}$
PMID: $\underline{31376271}$

CLaura Ospina-Pinillos, Tracey Davenport, Antonio Mendoza Diaz, Alvaro Navarro-Mancilla, Elizabeth M Scott, Ian B Hickie. Originally published in the Journal of Medical Internet Research (http://www.jmir.org), 02.08.2019. This is an open-access article distributed under the terms of the Creative Commons Attribution License (https://creativecommons.org/licenses/by/4.0/), which permits unrestricted use, distribution, and reproduction in any medium, provided the original work, first published in the Journal of Medical Internet Research, is properly cited. The complete bibliographic information, a link to the original publication on http://www.jmir.org/, as well as this copyright and license information must be included. 